\title{
Recovery of bioactive compounds from Arbutus unedo L. fruits: Comparative optimization study of maceration/microwave/ultrasound extraction techniques
}

\author{
Bianca R. Albuquerque $^{\mathrm{a}, \mathrm{b}}$, M.A. Prieto ${ }^{\mathrm{a}, \mathrm{c}, *}$, J.A. Vazquez ${ }^{\mathrm{d}}$, Maria Filomena Barreiro ${ }^{\mathrm{a}, \mathrm{e}}$, \\ Lillian Barros ${ }^{\mathrm{a}}$, Isabel C.F.R. Ferreira ${ }^{\mathrm{a}, *}$ \\ a Centro de Investigação de Montanha (CIMO), Instituto Politécnico de Bragança, Campus de Santa Apolónia, 5300-253 Bragança, Portugal \\ b Departamento de Alimentos, Universidade Tecnológica Federal do Paraná, Campus de Medianeira, Avenida Brasil, 4232 CEP 85884-000, Caixa Postal 271, Medianeira, \\ Brazil \\ ${ }^{\mathrm{c}}$ Nutrition and Bromatology Group, Faculty of Food Science and Technology, University of Vigo, Ourense Campus, E32004 Ourense, Spain \\ ' Grupo de Reciclado y Valorización de Materiales Residuales (REVAL), Instituto de Investigacións Mariñas (IIM-CSIC), r/Eduardo Cabello, 6, Vigo 36208, Galicia, Spain \\ ${ }^{\mathrm{e}}$ Laboratory of Separation and Reaction Engineering - Laboratory of Catalysis and Materials (LSRE-LCM), Polytechnic Institute of Bragança, Campus Santa Apolónia, \\ 1134, 5301-857 Bragança, Portugal
}

\section{A R T I C L E I N F O}

\section{Keywords:}

Arbutus unedo L. fruits

Compositional analysis

Antioxidant

Conventional and non-conventional extraction techniques

Maceration/microwave/ultrasound assisted

extraction

Response surface methodology

\begin{abstract}
A B S T R A C T
The aim of this work was to produce an extract rich in different bioactive compounds from Arbutus unedo L. fruits to enhance its possible valorization and commercialization. The conditions of the main variables of maceration, microwave, and ultrasound assisted extractions (MA, MAE and UAE, respectively) were optimized and compared in terms of its composition (based on the total material extracted, total content in carbohydrates, phenolic and flavonoid compounds) and its preservative potential (based on the response of four in vitro antioxidant assays). The key variables of each extraction technique (time, temperature or power and hydroalcoholic mixture) were evaluated by specific experimental designs using response surface methodology. Mathematical models were developed and numerical optimal values for each extraction technique and response were achieved. Regarding the extraction of target compositional compounds, MAE was the most efficient, closely followed by MA. In terms of its preservative potential, MAE was the most suitable solution, but MA gave similar results at lower temperatures $\left(\sim 90^{\circ} \mathrm{C}\right)$. Globally, MA and MAE were the best options conducting to optimal solutions using reduced amounts of ethanol. UAE required higher ethanol contents $(\sim 60 \%)$. The results showed alternatives to obtain extracts of $A$. unedo fruits, supporting their potential to be exploited at industrial level.
\end{abstract}

\section{Introduction}

The strawberry tree (Arbutus unedo L.) is a plant native of the Mediterranean, producing berries with a high nutritional value due to its rich content in sugars (Ayaz, Kucukislamoglu, \& Reunanen, 2000; Barros, Carvalho, Morais, \& Ferreira, 2010; Miguel, Faleiro, Guerreiro, \& Antunes, 2014; Özcan \& Hacıseferoğulları, 2007; Pinela, Barros, Carvalho, \& Ferreira, 2012). In addition, the fruit's composition includes other bioactive components such as phenolic compounds, vitamins and carotenoids that have been related with their strong preservative properties (Albuquerque et al., 2016; Barros et al., 2010; Fattore et al., 2016; Guimarães et al., 2014; Montesano, Cossignani, D'Arco, Simonetti, \& Damiani, 2006). In this context, the incorporation of this non-industrialized fruit in commercial products would allow the replacement of synthetic additives such as preservatives, enhancing the nutritional value of the product while providing a sweet perception.

Natural preservatives can be obtained from floral parts of plants, fruit juices and mushrooms due to their high content in bio-molecules with strong antioxidant potential (Carocho, Barreiro, Morales, \& Ferreira, 2014; Carocho \& Ferreira, 2013; Naziri, Nenadis, Mantzouridou, \& Tsimidou, 2014). The use of natural preservatives, instead of artificial ones, is perceived by consumers as a beneficial step towards a healthier food-lifestyle. As so, in the last decade, the nutraceutical market has increased the demand for the production and incorporation of natural preservatives in a wide range of products trying to satisfy these requirements (Ahmad, Ashraf, Ahmad, Ansari, \& Siddiquee, 2011; García-Moreno et al., 2014). However, as any change, this "healthy revolution" in the type of additives applied in of the food

\footnotetext{
* Corresponding authors at: Centro de Investigação de Montanha (CIMO), Instituto Politécnico de Bragança, Campus de Santa Apolónia, $5300-253$ Bragança, Portugal.

E-mail addresses: iferreira@ipb.pt (M.A. Prieto), iferreira@ipb.pt (I.C.F.R. Ferreira).
} 
market is suffering a delay, partly due to the adaptation needed in the industrial sector. One of the relevant problems is the multifaceted processes needed to obtain bioactive compounds for the formulation of more natural additives (Bursać Kovačević et al., 2018). The production of these additives includes labor-intensive steps such as the matrix selection and separation, and industrial processes such as drying, extraction, separation and purification. Although all of them are known to contribute to the functional quality, the extraction process has been pointed out as the core step in the production process of natural additives (Belwal, Bhatt, Rawal, \& Pande, 2017; Montesano et al., 2008; Naviglio, Montesano, \& Gallo, 2015; Zhu et al., 2016).

The current goal is to design extraction processes that combine reasonable energy requirements with short times and reduced use of solvents (particularly organic solvents), maintaining the extraction efficiency of conventional solid-liquid extractions such as the Soxhlet system and the simplicity of the maceration extraction (ME) (Meullemiestre, Petitcolas, Maache-Rezzoug, Chemat, \& Rezzoug, 2016; Pinela et al., 2016; Wang \& Weller, 2006). Thus, non-conventional extraction techniques as microwave-assisted extraction (MAE) (Belwal et al., 2017; Périno, Pierson, Ruiz, Cravotto, \& Chemat, 2016; Simić et al., 2016) and ultrasound-assisted extraction (UAE) (Heleno et al., 2016; Meullemiestre et al., 2016; Tomšik et al., 2016) are being applied to obtain valuable nutritional and bioactive compounds from natural matrices. Academic and industrial sectors are joining efforts to report and compare the advantages and disadvantages of using these approaches, namely the impact on target matrices. In comparison with other techniques, MAE causes acceleration of the extraction process and reduction of solvent consumption, improving matrix deconstruction, thus promoting the release of larger amounts of compounds (Baiano, Luisa, Carmela, Contò, \& Del Nobile, 2014; Choi et al., 2011). UAE is one of the preferable alternative methods due to the cavitation effect caused that allows to reduce the solvent needed increasing the release of the desired compounds with low energy requirements (Meullemiestre et al., 2016; Zhu et al., 2016).

However, as recurrently reported (Galanakis, 2012; Tomšik et al., 2016), these alternative techniques accelerate the degradation rate of nutritional and bioactive compounds, which are affected by the intrinsic variables of each system. Thus, in MAE and ME systems the relevant variables are time $(t)$, temperature $(T)$ and the ethanol content in the hydroalcoholic mixture $(S)$, whereas in UAE the $T$ remains constant, being the key variables to consider $t$, ultrasound power $(P)$ and $S$. The patterns and interactions of these variables are crucial for the success of the extraction process of nutritional or bioactive compounds (Albuquerque et al., 2016; Heleno et al., 2016; Pinela et al., 2016; Tomšik et al., 2016), but its analytical solution is complex and requires intensive laboratory efforts with a high number of experimental combinations of the involved variables. These problems can be minimized by using response surface methodology (RSM), a statistical tool used to predict the optimum experimental conditions that maximize or minimize, individually or simultaneously, one or various independent variables (Bezerra et al., 2008; Ferreira et al., 2007; Wong et al., 2015).

Thereafter, the goal of this work was to optimize the conditions of ME, MAE and UAE techniques by applying a RSM design with the objective to produce an extract from $A$. unedo fruits rich in useful biocompounds in terms of its compositional and potential preservative features. The following characterizations were used to support the response criteria of the combinatory variable's conditions generated by the RSM design for each technique: (1) In terms of its composition, the extraction yield of the material produced, total sugars, phenolic and flavonoid contents; (2) In terms of its preservative potential, the activity determined through the concentration-time response according to four methods; two single electron transfer (SET) assays (the ABTS and DPPH in vitro assays, which are able to measure the global scavenging capacity of non-natural radicals), and two hydrogen atom transfer (HAT) assays (the $\beta$-carotene and crocin bleaching methods that use natural reaction radical species appropriate for the evaluation of antioxidant properties of lipophilic and hydrophilic components, respectively).

From the performed analyses several outcomes were defined: 1) to link each of the used extraction techniques to the individual conditions providing the highest ability to extract the target compounds or to maximize the preservative potential, as defined in the used response criteria; 2) to determine the optimal global extraction conditions among the used techniques (ME, MAE and UAE) having in view the production of a A. unedo fruits extract with maximized properties in terms of composition and preservative potential; 3 ) to propose diverse combinations of extraction conditions and techniques in order to maximize the response criteria in individually or relative terms assembled as a function of a desired purpose; and 4) to link the most promising maximization criteria (global, individual or relative) to obtain an antioxidant extract from $A$. unedo fruits for its incorporation in food-related products.

\section{Materials and methods}

\subsection{Source material}

The fruits of A. unedo L. (strawberry tree) from Ericaceae were gathered in the Natural Park of Montesinho territory, in Trás-osMontes, North-eastern Portugal. The botanical identification was confirmed by Dr. Ana Maria Carvalho (School of Agriculture, Polytechnic Institute of Bragança, Trás-os-Montes, Portugal) according with a previous report of the authors (Guimarães et al., 2013). The fruits were lyophilized (FreeZone 4.5, Labconco, Kansas City, MO, USA) and stored in a deep-freezer at $-20^{\circ} \mathrm{C}$ for subsequent analyses.

\subsection{Standards and reagents}

Water was treated in a Milli-Q water purification system (TGI Pure Water Systems, Greenville, SC, USA). All the chemicals and solvents were of analytical grade and purchased from common suppliers.

\subsection{Extraction techniques}

\subsubsection{Maceration extraction (ME)}

The lyophilized powdered fruit samples $(1 \mathrm{~g})$ were placed in a beaker with $20 \mathrm{~mL}$ of the required solvent and placed in a thermostatic water bath, at the defined temperature, under continuous electromagnetic stirring during the required extraction time. The variables and ranges tested were: time ( $t$ or $X_{1}, 20$ to $150 \mathrm{~min}$ ), temperature ( $T$ or $X_{2}$, 20 to $90^{\circ} \mathrm{C}$ ) and ethanol content ( $S$ or $X_{3}, 0$ to $100 \%$ ).

\subsubsection{Microwave-assisted extraction (MAE)}

MAE process was performed using a Biotage Initiator Microwave (Biotage $^{\circledR}$ Initiator $^{+}$, Uppsala, Sweden) using closed vessels. The lyophilized powdered samples $(1 \mathrm{~g})$ were extracted with $20 \mathrm{~mL}$ of solvent. In microwave systems, the pressure and $T$ are correlated and the applied power is linked to the needed $t$ to reach the selected $T$ or pressure. In consequence, $T$ was selected as the main variable and the microwave power was set to $400 \mathrm{~W}$. Under the selected conditions, the needed $t$ to reach the selected $T$ was always $<20 \mathrm{~s}$, thus guarantying a fast heating process (this time can be neglected face to the studied extraction time range). Therefore, the final variables and ranges tested were: $t\left(X_{1}, 1.6\right.$ to $45 \mathrm{~min}), T\left(X_{2}, 50\right.$ to $\left.145^{\circ} \mathrm{C}\right)$ and $S\left(X_{3}, 0\right.$ to $\left.100 \%\right)$.

\subsubsection{Ultrasound-assisted extraction (UAE)}

The UAE was carried out in an ultrasonic device (QSonica sonicators, model CL-334, Newtown, CT, USA). The lyophilized powdered samples $\left(2.5 \mathrm{~g}\right.$ ) were extracted with $50 \mathrm{~mL}$ at different times ( $t$ or $X_{1}, 5$ to $55 \mathrm{~min}$ ), power ranges ( $P$ or $X_{2}, 100$ to $400 \mathrm{~W}$ ) and ethanol content ( $S$ or $X_{3}, 0$ to $100 \%$ ), while temperature was monitored in order to be below $30-35^{\circ} \mathrm{C}$. 


\subsection{Extract isolation and purification}

The collected extracts were filtered (Whatman paper filter $n^{\circ} 4$ ) and then dried at $40^{\circ} \mathrm{C}$ in a rotary evaporator Büchi R-210 (Flawil, Switzerland). For purification, a $\mathrm{C}_{18}$ SepPak $^{\circledR}$ Vac 3 cc cartridge (Phenomenex) was used. After being activated with ethanol followed by water; sugars and more polar substances were removed by passing the column with $10-20 \mathrm{~mL}$ of water. Then the purified extract was further eluted with $10-15 \mathrm{~mL}$ of ethanol. The purified extract was dried at $40{ }^{\circ} \mathrm{C}$ to remove the ethanol and re-dissolved at known concentration.

\subsection{Evaluation of compositional parts of the extracted material}

- Residue material extracted (R) per gram of fruit (mg R/g F dw), was determined following the procedure reported by Mortensen et al. (1989). Briefly, the water content of the sample was evaporated at $80^{\circ} \mathrm{C}$ followed by a heating process at $104^{\circ} \mathrm{C}$ until a constant weight was reached.

- Total carbohydrate content (TS) was determined by the phenolsulphuric acid method using glucose as standard (Dubois, Gilles, Hamilton, Rebers, \& Smith, 1956; Strickland \& Parsons, 1968) and expressed in $\mathrm{mg}$ per $\mathrm{g}$ of $\mathrm{R}(\mathrm{mg} / \mathrm{g} \mathrm{R})$.

- Total phenolic content (TPC) was determined by the Folin-Ciocalteu method with some modifications (Pereira, Barros, Carvalho, \& Ferreira, 2011) using gallic acid as standard and expressed as mg of gallic acid equivalents (GAE) per $g$ of $\mathrm{R}$ (mg GAE/g R).

- Total flavonoid content (TFC) was determined by a colorimetric method as described by the authors (Barros et al., 2010) using catechin as a standard, and expressed as $\mathrm{mg}$ of catechin equivalents (CE) per $\mathrm{g}$ of $\mathrm{R}$ (mg CE/g R).

\subsection{Determination of the individual time-dose antioxidant capacity for SET and HAT assays}

SET (DPPH and ABTS) and HAT ( $\beta$-Carotene and Crocin) assays are rapid methods in which the indicator and radical species of the reaction can be adjusted to extend or shorten the time of the reaction. These assays are measured at a fixed time to evaluate the color change of the reaction. The initially chosen fixed points have a relevant impact on the obtained final results (Huang, Ou, Prior, \& Ronald, 2005; Prieto, Vázquez, \& Murado, 2014). Therefore, in SET and HAT assays, to avoid generating inconsistent responses, an intermediate approach for quantification of the antioxidant responses was used (Prieto et al., 2014b; Arts, 2004). The non-linear kinetic reactions were summarized by a standardized format in area units and the dose-response results of this area units were analyzed by a mathematical model. Other methodological procedures of those methods were kept as described in literature. Stock solutions, experimental procedure and quantification of the results are briefly described in the subsequent sections.

\subsubsection{Stock solutions and conditions of HAT antioxidant-based assays}

Stock solutions were prepared and kept in a translucent tube at $4{ }^{\circ} \mathrm{C}$ in darkness. The solvents and other chemicals used for the preparation of both reagents were of analytical grade. The absorbance of both stock radical solutions was measured daily. If any loss of the free radical activity was noticed, the fresh solution was prepared (Ozgen, Reese, Tulio, Scheerens, \& Miller, 2006). Conditions of the reactions and stock solutions are described next:

2.6.1.1. $\beta$-Carotene bleaching inhibition method. $\beta$-Carotene bleaching inhibition method ( $\beta C M)$ (Marco, 1968; Prieto, Murado, RodríguezAmado, \& Vázquez, 2012): $2 \mathrm{mg}$ of $\beta$-carotene $(\beta \mathrm{C}, 1 \mu \mathrm{M}$ in the final reaction), $0.25 \mathrm{~mL}$ of linoleic acid and $2 \mathrm{~g}$ of Tween- 40 were dissolved in $20 \mathrm{~mL}$ of chloroform, vigorously mixed, followed by chloroform evaporation $\left(45^{\circ} \mathrm{C} / \sim 15 \mathrm{~min}\right)$. To the resulting oily residue $300 \mathrm{~mL}$ of buffered Mili-Q water ( $100 \mathrm{mM}$ Briton, $\mathrm{pH}=6.5$ ) at $45^{\circ} \mathrm{C}$ were added.
The absorbance at $470 \mathrm{~nm}$ of the prepared reagent was $\sim 1.40$.

2.6.1.2. Crocin method. Crocin method (CM) (Bors, Michel, \& Saran, 1984; Prieto, Vázquez, \& Murado, 2015): 4 mg of crocin (Cr, $100 \mu \mathrm{M}$ in the final reaction) and $75 \mathrm{mg}$ of AAPH $(7.68 \mathrm{mM}$ in the final reaction) were dissolved in $30 \mathrm{~mL}$ of a $100 \mathrm{mM}$ Briton buffer, $\mathrm{pH}=5.5$, in Mili-Q water. The absorbance at $450 \mathrm{~nm}$ of the prepared reagent was $\sim 1.40$ at $40^{\circ} \mathrm{C}$.

2.6.2. Stock solutions and conditions of SET antioxidant-based assays 2.6.2.1. DPPH radical scavenging activity. The $\mathrm{DPPH}^{\cdot}{ }^{+}$radical scavenging activity (DPPH): This method was assessed as described previously (Jiménez-Escrig, Jiménez-Jiménez, Sánchez-Moreno, \& Saura-Calixto, 2000; Prieto, Curran, Gowen, \& Vázquez, 2015; Sharma \& Bhat, 2009). Briefly, 1,1-diphenyl-2-picrylhydrazyl (DPPH) stock solution was prepared in methanol $(0.50 \mathrm{~g} / \mathrm{L})$. For testing the potential of antioxidants, the stock solution was diluted 10 -fold to provide an absorbance of $\sim 1.2$ units at $515 \mathrm{~nm}$ at $30^{\circ} \mathrm{C}$.

2.6.2.2. ABTS radical scavenging activity. The $\mathrm{ABTS}^{+}$radical scavenging activity (ABTS): This method was assessed as described previously (Obón, Castellar, Cascales, \& Fernández-López, 2005; Prieto, Curran, et al., 2015; Re et al., 1999). Briefly, the stock solution was prepared in distilled water by mixing $4 \mathrm{mM}(21.95 \mathrm{mg} / 10 \mathrm{~mL})$ of ABTS (2,2' - azinobis-(3-ethyl-benzothiazoline- 6-sulphonic acid)) with $1.5 \mathrm{mM}$ of potassium persulfate $\left(\mathrm{K}_{2} \mathrm{~S}_{2} \mathrm{O}_{8}, 4.03 \mathrm{mg} / 10 \mathrm{~mL}\right)$. In order to convert ABTS completely into its radical cation (ABTS $\cdot{ }^{+}$), the reaction mixture was left in the dark at room temperature for $12-16 \mathrm{~h}$, before use. To test the potential of antioxidants, the stock solution was diluted 22 -fold with phosphate buffered saline $(5 \mathrm{mM}, \mathrm{pH} 7.4)$ to provide an absorbance of $\sim 1.2$ units at $414 \mathrm{~nm}$ at $30^{\circ} \mathrm{C}$.

\subsubsection{Experimental procedure}

The procedure was performed by adding $50 \mu \mathrm{L}$ of the sample and $250 \mu \mathrm{L}$ of the reagent into the wells $(350 \mu \mathrm{L})$ of a microplate reader of 96 units (Thermo Scientific Nunc 96-Well Polypropylene MicroWell Plate with flat bottom). The reduction of ABTS ${ }^{+}$and DPPH ${ }^{+}{ }^{+}$(respectively, $15 \mathrm{nM}$ and $30 \mathrm{nM}$ in the final solution) and bleaching of $\beta C$ and $\mathrm{Cr}$ compounds (respectively, $1 \mu \mathrm{M}$ and $100 \mu \mathrm{M}$ in the final solution) were followed by monitoring the decrease of absorbance along the reaction. The microplate reader (Multiskan Spectrum Microplate Photometers from Thermo Fisher Scientific) was programmed to read the absorbance, at the respective wavelengths, every minute during a period of $300 \mathrm{~min}$ under stirring at $660 \mathrm{cycles} / \mathrm{min}$ ( $1 \mathrm{~mm}$ amplitude). The extracts were analyzed kinetically for eight different concentrations obtained by serial dilution $(1 / 1,1 / 2,1 / 4,1 / 8,1 / 16,1 / 32,1 / 64$ and the control) with distilled water.

\subsubsection{Normalization of the time-dose response effects}

The area under the curve (AUC) (Eq. (1)), computed by a numerical integration method such as the trapezoidal rule, proved to be a highly robust criterion, able to summarize in a single value the global feature of the kinetic profile.

$A U C=\frac{R_{1} \Delta t_{1}}{2}+\sum_{i=2}^{i=n-1} R_{i} \Delta t_{i}+\frac{R_{n} \Delta t_{n}}{2}$

where $i$ is the number of data measured over time $t, R_{i}$ are the responses along an arbitrary time series, and $\Delta t$ is the interval between measurements.

Once the AUC dose-response is obtained for all the compounds and methods, the results need to be normalized. However, HAT and SET assays requires different normalizations as described below:

- For HAT based assays, the AUC are normalized against the AUC obtained with the control, leading to the formulation of the relative 
area units or protected substrate $(P)$ as defined by other authors (Dávalos, Gómez-Cordovés, \& Bartolomé, 2004; Huang, Ou, Hampsch-Woodill, Flanagan, \& Prior, 2002; Naguib, 2000) for antioxidant responses. The normalized equation for HAT assays can be presented as follows:

$P(t, D)=S_{0}\left(\frac{A U C_{t}^{C}-A U C_{t}^{D}}{A U C_{t}^{C}}\right)$

where $A U C_{C}$ and $A U C_{A}$ are the area units corresponding to the kinetic profiles found in the absence (control, $C$ ) and presence of an antioxidant concentration $A$, respectively, and $S_{O}$ is the initial substrate in the reaction (for the CM $100 \mu \mathrm{M}$ of $\mathrm{Cr}$ and for the $\beta \mathrm{CM}$ is $1 \mu \mathrm{M}$ of $\beta C$ ). Thus, the $P$ value increases with the concentration and the antioxidant power of the compound.

- For SET based assays the AUC provides directly the depletion of $\mathrm{DPPH} \cdot{ }^{+}$and ABTS $\cdot^{+}$radicals. Therefore, the best normalization approach would be to rearrange the response as a function of the reduced radical molecules, as follows:

$R^{\cdot+}(t, D)=R_{0}^{\cdot+} \times\left(1-\frac{A U C_{t}^{D}}{A U C_{t}^{C}}\right)$

in which $R^{\cdot+}$ is the bleached radical response measured as a function of time $(t)$ and dose of an antioxidant (A). $R_{0}{ }^{+}$is the initial concentration of the radical form of the compound (for the DPPH the substrate is equivalent to $15 \mathrm{nM}$ of DPPH ${ }^{+}$and for the ABTS is $30 \mathrm{nM}$ of ABTS ${ }^{+}$). $A$ and $C$ are the $A U C$ of kinetic curves for each dose of the antioxidant (A) and the control (C), respectively. Thus, the $R^{\cdot+}$ value increases with the concentration and the antioxidant power of the compound.

\subsubsection{Quantification time-dose response effects}

Once the time effect is summarized in terms of area units, for both reactions, the variation of $P$ and $R^{\cdot+}$ as function of the concentration of the mixture of antioxidants extracted, the Weibull $(W)$ cumulative distribution function (Weibull \& Sweden, 1951) was used for assessing the dose-response effects. Thus, the response effect of increasing concentrations of an $A$ can be described in general terms as follows:

$W(t, A)=K\left\{1-\exp \left[-\ln (2)^{1-a}\left(\frac{2 V_{m}}{K a} A\right)^{a}\right]\right\}$

where $K$ is the averaged maximum protected substrate, asymptotic value of the response, the parameter $V_{m}$ corresponds to the average number of protected molecules $(\mathrm{Cr}$ and $\mathrm{BC})$ or reduced radical molecules (DPPH $\cdot{ }^{+}$and ABTS $\cdot{ }^{+}$) per weight of R obtained $(\mu \mathrm{M} / \mathrm{mg}$ R for $\mathrm{CM}$ and $\beta \mathrm{CM}, \mathrm{nM} / \mu \mathrm{g} \mathrm{R}$ for DPPH and ABTS), and $a$ is a shape parameter related to the slope of potential profiles $(a<1)$, first order kinetic $(a=1)$ and a variety of sigmoidal profiles $(a>1)$.

In addition, the typical value used to evaluate the antioxidant responses, the concentration needed to reach $50 \%$ of the maximum protective effect (the so called $I C_{50}$ ), was determined (for comparative purposes with other studies) according to Eq. (4) as follows:

$I C_{50}=\frac{K a \ln 2}{2 V_{m}} ;$ therefore $W(t, A)=K\left\{1-\exp \left[-\ln 2\left(A / I C_{50}\right)^{a}\right]\right\}$

\subsubsection{Evaluated commercial food antioxidants}

The antioxidant activity of the extracts was compared to that of different commercial antioxidants, which are listed below:

(a) Butyl-hydroxyanisole (BHA, E320): a synthetic antioxidant mainly used as preservative in lipophilic and hydrophilic media.

(b) Butyl-hydroxytoluene (BHT, E321): a synthetic lipophilic antioxidant used as food additive.

(c) Propyl 3,4,5-trihydroxybenzoate (PG, E310): an antioxidant commonly added to lipophilic foods to prevent oxidation. (d) (2R)-2,5,7,8-tetramethyl-2-[(4R,8R)-(4,8,12-trimethyltridecyl)]-6chromanol (TOC, E306): a lipophilic compound useful for its antioxidant properties.

(e) 6-Ethoxy-2,2,4-trimethyl-1.2-dihydroquinoline (ETX, E324): a synthetic lipophilic preservative commonly used in animal feeds.

(f) Tert-Butylhydroquinone (TBHQ, E319): a synthetic and highly effective antioxidant for foods.

(g) 6-Hydroxy-2,5,7,8-tetramethylchroman-2-carboxylic acid (TRO): a water-soluble antioxidant compound used in biological or biochemical applications for oxidation inhibition purposes.

\subsection{Response surface methodology}

\subsubsection{Experimental design}

From a combination of single variable preliminary experiments, previous extractions performed in our laboratory and bibliographic survey, the relevant variables and the appropriate tested ranges for each of the studied extraction techniques were selected and tested. The study of the impact of all independent variables was carried out using one-factor-at-a-time, to pick the most significant ones, and to determine their initial range. Through the analysis of the experimental results (data not shown), $X_{1}$ (time in min), $X_{2}$ (temperature in ${ }^{\circ} \mathrm{C}$ or power in W) and $X_{3}$ (ethanol content in \%) were chosen as relevant variables for the RSM design. A detailed description of the selected ranges for the variables chosen in each technique is described in Table A1 (Supplemental material section). The solid/solvent ratio was kept constant $(30 \mathrm{~g} / \mathrm{L})$ in all techniques. Therefore, the combined effect of three variables on the maximization process of the responses (composition and antioxidant power) was studied using a circumscribed central composite design (CCCD). The obtained responses within the use of 20 independent combinations of which six were replicas at central point of the experiment and five levels for each factor were necessary. The mathematical expressions used to calculate the design distribution, code and decode the tested variables can be found in detail in the Supplemental section.

\subsubsection{Mathematical modelling}

The model for the analysis of the produced responses follows this second-order polynomial equation:

$Y=b_{0}+\sum_{i=1}^{n} b_{i} X_{i}+\sum_{\substack{i=1 \\ j>i}}^{n-1} \sum_{j=2}^{n} b_{i j} X_{i} X_{j}+\sum_{i=1}^{n} b_{i i} X_{i}^{2}$

where $Y$ is the dependent variable (response variable) to be modelled, $X_{i}$ and $X_{j}$ define the independent variables, $b_{o}$ is the constant coefficient, $b_{i}$ is the coefficient of linear effect, $b_{i j}$ is the coefficient of interaction effect, $b_{i i}$ the coefficients of quadratic effect and $n$ is the number of variables. The experimental responses for the RSM in the ME, UAE and MAE were: 1) the composition of the $\mathrm{R}$ extracted per fruit dry weight (mg R/g F dw), TS (mg/g R), TPC (mg/g R) and TFC (mg/g R); and the parametric responses of the time-dose dependent parameter of $V_{m}$ of the antioxidant methods of ABTS (nM ABTS. ${ }^{+} / \mu \mathrm{g}$ R), DPPH (nM DPPH $\left..{ }^{+} / \mu \mathrm{g} \mathrm{R}\right), \mathrm{CM}(\mu \mathrm{M} \mathrm{Cr} / \mathrm{mg} \mathrm{R})$ and $\beta \mathrm{CM}(\mu \mathrm{M} \beta \mathrm{C} / \mathrm{mg} \mathrm{R})$.

Although the statistical consistent model parameters obtained are empirical and cannot be associated with a mechanistic meaning, they are useful to predict the results of untested operation conditions (Pinela et al., 2016). The sign of the effect marks the response performance. In this way, when a factor has a positive effect, the response is higher at the high level and when a factor has a negative effect, the response is lower at the high level. The higher the absolute value of a coefficient, the more important the weight of the corresponding variable (Heleno et al., 2016).

2.7.3. Procedure to optimize the variables to a maximum response For optimization of purposes, a maximization process of the 
different criteria responses analyzed by RSM model was performed, using a simple method tool to solve non-linear problems (Heleno et al., 2016; Pinela et al., 2016). Limitations were made to the variable coded values to avoid unnatural conditions (i.e., times lower than 0 ).

\subsection{Numerical methods, statistical analysis and graphical illustrations}

The fitting procedures of the equations to the experimental responses data (R, TS, TPC and TFC) and parametric values (parameter of $V_{m}$ of ABTS, DPPH, CM and $\beta \mathrm{CM}$ antioxidant methods) were performed on a Microsoft Excel spreadsheet. Coefficients estimation and statistical calculations according to the proposed equations were carried out in three phases:

1) The estimation of coefficients was obtained by minimization of the sum of quadratic differences between the observed and model-predicted values, using the nonlinear least-squares (quasi-Newton) method provided by the macro Solver in Microsoft Excel (Torrado et al., 2013).

2) The significance of the coefficients was determined by the parametric confidence intervals calculated using the 'SolverAid' model simplified by dropping terms, which were not statistically significant ( $p$-value $>$.05) (Prieto, Curran, et al., 2015).

3) The uniformity of the model was checked by applying the following statistical assessment criteria: a) The $R^{2}$ and $R_{\text {adj }}^{2}$ were interpreted as the proportion of variability of the dependent variable explained by the model; b) Bias and accuracy factors of all equations were calculated to evaluate the quality of the fitting to the experimental data, such as the mean squared error (MSE), the root mean square error (RMSE) and the mean absolute percentage error (MAPE); and c) The Durbin-Watson coefficient (DW) was used to check if the residuals of the model were not autocorrelated.

\section{Results and discussion}

3.1. Mathematical models derived from the RSM for a CCCD with three variables and statistical assessment of the parametric values obtained and the fitting results produced

The experimental results obtained for the RSM design are shown in Table 1, using the responses defined for the composition analysis (R, TS, TPC and TFC) and the $V_{m}$ parametric value for the antioxidant potential of the extracts as assessed by several evaluation methods (ABTS, DPPH, $\mathrm{CM}$ and $\beta \mathrm{CM}$ ) for each extraction technique tested (ME, MAE and UAE). By fitting the second-order polynomial model of Eq. (6) to the obtained responses, and using nonlinear least-squares estimations, the parametric values, the parametric confidence interval, and the basic fitting statistics were obtained and presented in Table 2. The resulting models for each assessed extraction techniques are the following:

For the ME system:

$$
\begin{aligned}
Y_{R}^{M E}= & 603.5+10.0 t+21.4 T-11.8 S-12.1 t^{2}-4.7 T^{2}-6.2 S^{2}+5.3 t T \\
& -7.0 t S \\
Y_{T S}^{M E}= & 653.5-14.3 t-7.1 S-4.6 t^{2}-28.5 T^{2}+10.0 t T+14.2 t S \\
Y_{T P C}^{M E}= & 46.4-6.3 t-15.7-17.2 S-3.3 t^{2}+23.0 S^{2} 16.5 T S \\
Y_{T F C}^{M E}= & 29.6+1.8 t+14.3 T-2.7 S+4.4 T^{2}-5.5 S^{2}-6.5 T S \\
Y_{A B T S}^{M E}= & 1.9-0.08 t+0.03 T-0.3 S+0.6 t^{2}+0.26 T^{2}+0.22 S^{2}+0.02 t T \\
& -0.02 t S-0.3 T S \\
Y_{D P P H}^{M E}= & 0.7+0.02 t+0.04 T+0.03 S-0.06 S^{2}-0.05 T S \\
Y_{C M}^{M E}= & 76.2+2.8 t+29.6 T-7.8 S-1.8 t^{2}+8.9 T^{2}-7.5 S^{2}-2.8 t S \\
& -10.9 T S
\end{aligned}
$$

$$
\begin{aligned}
Y_{\beta C M}^{M E}= & 57.8-3.3 t-2.6 T-4.7 S-2.6 t^{2}-1.2 T^{2}+3.4 S^{2}-1.2 T^{2} \\
& +3.4 S^{2}-1.2 t S+2.7 T S
\end{aligned}
$$

For the MAE system:

$Y_{R}^{M A E}=593.5+23.3 t-26.5 S+7.8 T 2-21.1 S 2-10.3 t S+48.8 T S$

$Y_{T S}^{M A E}=632.3-28.9 t+17.4 T-50.9 S-12.5 t 2-17.5 T 2+60.2 S 2$

$+37.5 t S-44.6 T S$

$Y_{T P C}^{M A E}=21.5-12.2 T+25.0 S+9.0 t 2+2.3 T 2+32.0 S-17.7 t S-2.7 T S$

$Y_{T F C}^{M A E}=30.0+4.4 T-2.6 T-4.7 \mathrm{~S}-2.6 t 2-1,2 T 2+3.4 S 2-1.3 t T$ $+2.7 T S$

$Y_{A B T S}^{M A E}=1.9-0.08 t+0.17 T+0.23 S-0.2 S 2+0.14 t S-0.19 T S$

$Y_{D P P H}^{M A E}=0.5-0.05 t+0.02 T-0.06 S-0.02 t 2-0.02 T 2-0.05 S 2$

$$
-0.07 t T+0.08 t S-0.05 T S
$$

$Y_{C M}^{M A E}=95.6-5.0 t+19.0 T-20.4 S-5.7 t^{2}-20.2 S^{2}-2.3 t T+13.3 t S$ $-6.7 T S$

$Y_{\beta C M}^{M A E}=33.6+2.3 t-10.8 T+8.0 t 2+2.6 T 2+12.2 S 2-15.5 t T-5.5 t S$ $+4.1 T S$

For the UAE system:

$Y_{R}^{U A E}=633.1+10.4 t+27.3 P-37.5 S-36.3 S 2+9.33 t P+21.7 t S$ $-17.8 P S$

$Y_{T S}^{U A E}=623.4+9.5 t-2.7 P-4.2 S-1.1 t 2-3.5 t P+7.00 t S+18.3 P S$

$Y_{T P C}^{U A E}=17.9-9.24 t-5.2 P+28.7 S+2.8 t 218.6 S 2-3.8 t P-5.3 t S$ $+1.6 t P$

$Y_{T F C}^{U A E}=30.2-6.1 t 2-6.9 P 2-8.1 S 2+3.2 t P-0.7 t S-1.2 P S$

$Y_{A B T S}^{U A E}=1.9-0.03 t-0.05 P+0.12 S-0.28 S 2+0.06 t S-0.04 P S$

$Y_{D P P H}^{U A E}=0.6-0.02 P+0.02 S-0.05 t 2-0.05 P 2-0.10 S 2+0.02 t P$

$+0.05 t S+0.02 P S$

$Y_{C M}^{U A E}=81.9-4.4 P-12.9 t 2-15.4 P 2-11.9 S 2=13.7 t P-10.5 t S$ $-7.6 P S$

$Y_{\beta C M}^{U A E}=49.7-15.9 t-5.6 P+39.2 S+5.3 t 2+11.7 S 2+4.9 P S$

Those coefficients, which showed effects at coefficient interval values $(\alpha=0.05)$ higher than the parameter value, were consider as nonsignificant (ns) and were not used for the model development. Eqs. (7) to (30) translate the response patterns for the composition and antioxidant capacity response criteria for the ME, MAE and UAE evaluated methods.

For all the studied techniques, and for each response criteria, the linear (except for TFC obtained by UAE), quadratic and interactive effects were found essential. The parameter values related with the interactive effects of the obtained responses justify the need of the RSM to optimize the extraction responses. If one-variable-at-the-time analysis was performed the strong interactive effects displayed among the variables would make impossible to detect an optimal condition.

In terms of statistical analysis of the resultant fitting of the models to the responses, the lack-off-fit test used to assess the competence of the models showed that the significant parameters (Table 2) were highly consistent and if any were suppressed the reached solution would not be statistically consistent. This was also verified by the achieved high 

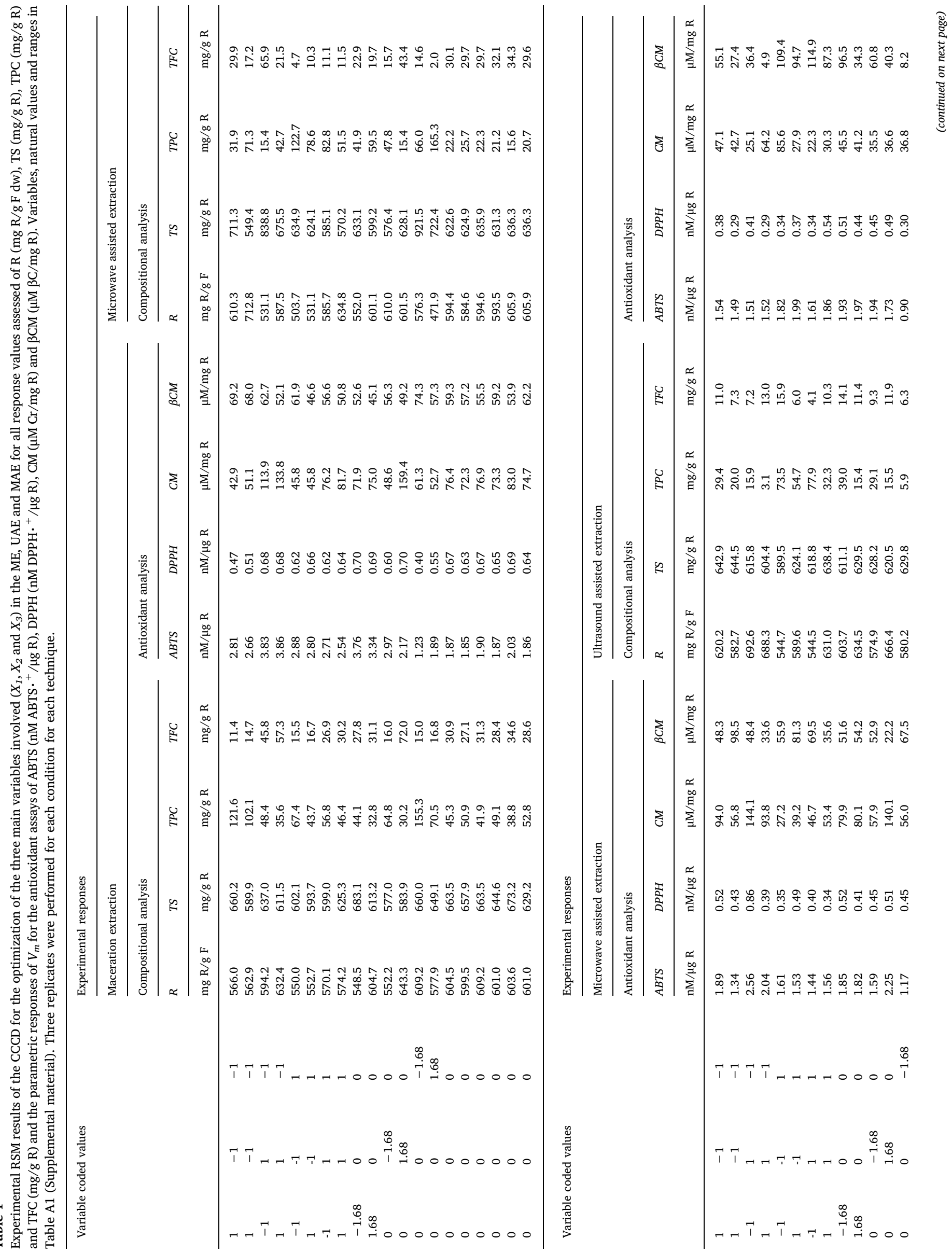


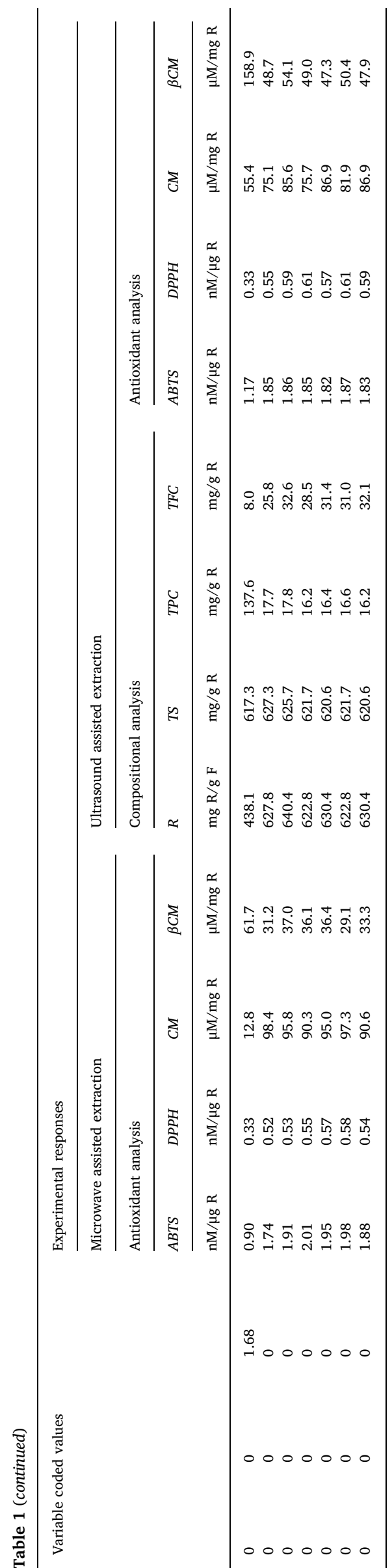

$\mathrm{R}^{2}$ values ( $\sim 0.9$ in almost all responses), which indicate the percentage of variability explained by the model (Table 2). The residuals distribution was always randomly dispersed around zero without autocorrelations. Additionally, the agreement between the experimental and predicted values implies an acceptable explanation of the obtained results by the used independent variables. Therefore, the proposed Eqs. (7) to (30) are completely functional and adequate to be used for prediction and process optimization.

\subsection{Predicted patterns of the response criteria assessed}

The profile patterns derived from the parametric values predicted by the second order polynomial described by Eq. (6) (Table 2) can be outlined by graphical representation. Figs. 1 and 2 displays a 3D graphical illustration for the compositional response analysis (R, TS, TPC and TFC), whereas Fig. 3 shows the results of the preservative potential (ABTS, DPPH, CM and $\beta C M$ ).

\subsubsection{Compositional response analysis}

Fig. 1 shows the predicted surfaces for the results of the R produced (mg R/g) by the combination of the three involved variables $(t, T$ or $P$ and $S$ ) in each technique assessed (ME, MAE and UAE). Fig. 1 is divided in three columns one for each technique, and each column is divided into two sections (A and B). Section A shows the 3D surface plots for the three possible variable combinations produced. The binary action between variables is presented when the excluded variable is positioned at the center of the experimental domain (see Table A1, Supplementary material). Section B illustrates the capability to predict the obtained results and the residual distribution as a function of each one of the considered variables. The results presented in Fig. 1 reveals that ME and UAE techniques, in almost all combinations, provided optimal conditions in which the response is maximized.

Fig. 2 shows the summary of the optimized isolines projections for the combination of the three main variables involved in ME, MAE and UAE of the three compositional responses of TS, TPC and TFC (mg/g R). Each of the contour graphs represents the projection in XY plane of the predicted theoretical 3D responses. In addition, Fig. A1 shows the 3D representation of the isolines projection presented in Fig. 2 as it was performed for the R response in Fig. 1.

In general terms, from Figs. 1, 2 and A1 the following conclusions can be drawn:

- In ME, the variables $t$ and $T$ have a positive effect on the extraction yield of R, and the variable $S$ has a negative effect. For TS, it is noted that the variables $t$ and $S$ have a negative effect and the variation $T$ has a linear non-significant effect. For TPC, all variables have a negative effect, such phenomena may be related with the degradation of the phenolic compounds as the temperature increase, as well as with prolonged extraction times (Liyana-Pathirana \& Shahidi, 2005; Thoo, Ho, Liang, Ho, \& Tan, 2010). For TFC it is noted that the extraction is benefited with $t$ and $T$.

- Using MAE technique, the variable $t$ has a positive effect and $S$ a negative effect and the variation of $T$ did not produce an individual significant effect.

- For UAE, most of the responses give optimum values close to the center of the experimental design. Some studies focusing on the extraction of phenolic compounds, such as flavonoids and antioxidants from vegetal origin, have demonstrated the achievement of good efficiencies when using UAE (Ghasemzadeh, Jaafar, Karimi, \& Rahmat, 2014; Meullemiestre et al., 2016; Zhu et al., 2017).

\subsubsection{Preservative potential analysis}

The preservative effects can be evaluated using a large variety of assays, each one based on a specific mechanism of action, including HAT, SET, reducing power, and metal chelation, among others (Márcio Carocho \& Ferreira, 2013; Shahidi \& Zhong, 2015). For this reason, it is 


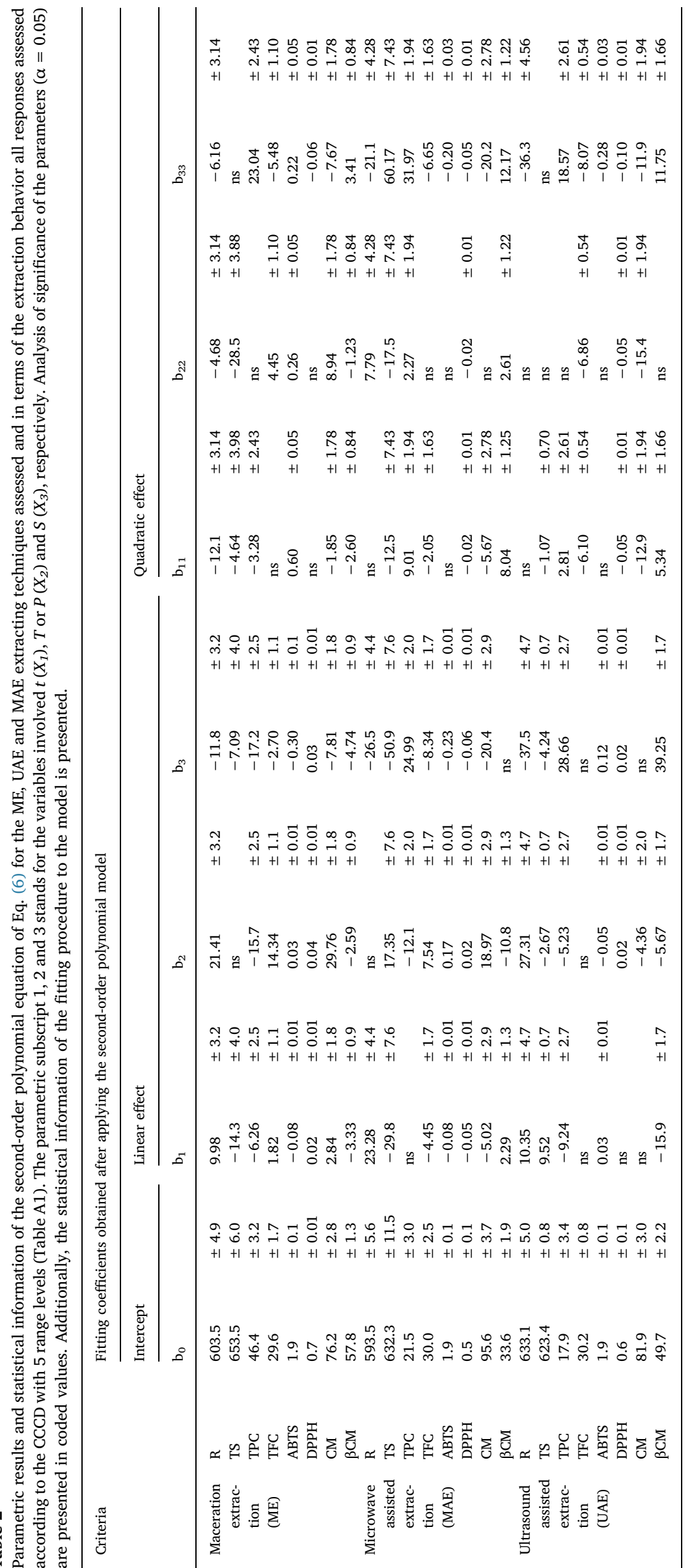

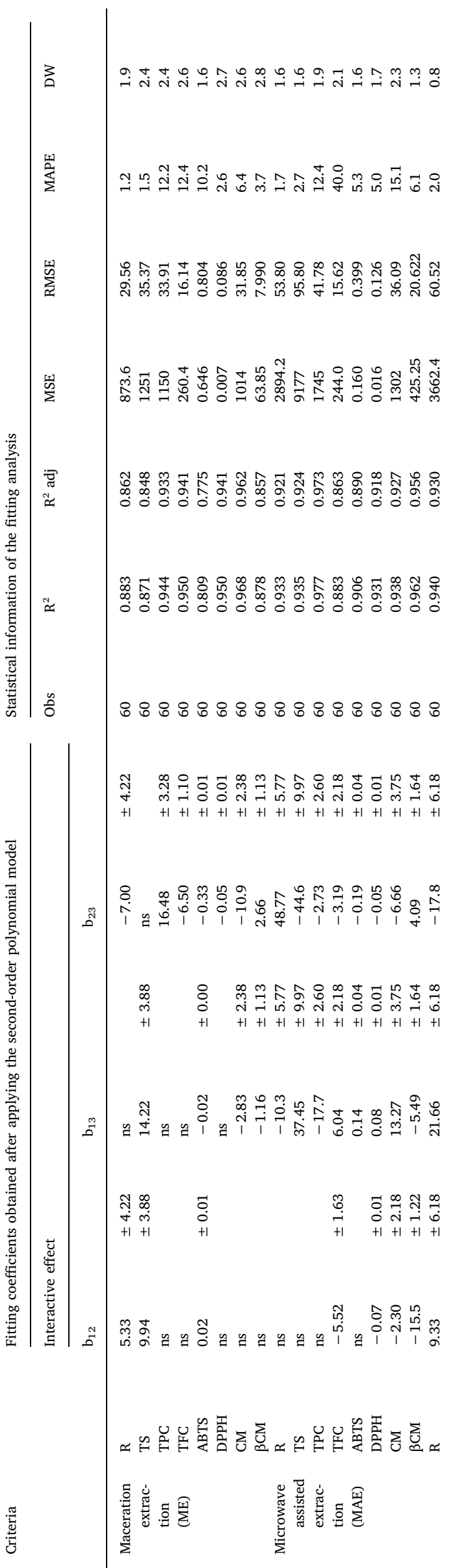


important to understand the mechanisms behind the selected assays for a suitable evaluation of the antioxidant potential. ABTS and DPPH are two of the most common SET based assays. Additionally, CM and $\beta \mathrm{CM}$ are two HAT based assays, appropriate for the antioxidant discrimination between hydrophilic $(H)$ and lipophilic $(L)$ matrices, respectively, which can provide useful information in the study of complex natural extracts containing components with variable degrees of polarity (Prieto, Murado, Vázquez, \& Curran, 2013; Prieto \& Vázquez, 2014).

Table A2 (Supplementary material) and Table A3 (Supplementary material) show the non-linear parametric analysis after the time-dose response analysis. Table A2 shows the parametric values obtained for $\mathrm{CM}$ and $\beta \mathrm{CM}$ antioxidant assays, whereas Table A3 presents the values obtained for ABTS and DPPH antioxidant assays. These parameters were obtained after assessing the time-dose response of each produced extract at the conditions planned in the CCCD (Table A1). The antioxidant responses were characterized by the parameter $V_{m}$ that describes a singular feature of the response and presented in Table 1. For more information regarding the complexity of the antioxidant evaluation, specific data can be found elsewhere (Prieto et al., 2013; Prieto, Curran, et al., 2015). The parameter $V_{m}$ shows the average specific weight of extracted material $\mathrm{R}$ needed to protect $\mathrm{Cr}$ or $\beta C$ substrate in HAT based assays ( $\mu \mathrm{M}$ of the protected substrate of $\mathrm{Cr}$ or $\beta \mathrm{C} / \mathrm{g} \mathrm{R}$ ) or to capture the radicals produced in SET based assays (nM of DPPH $\cdot^{+}$or ABTS.$^{+}$radicals/g R). The value provides a solution with a maximal predictability, where high $V_{m}$ values signify the most powerful antioxidant. There are a diverse number of compounds that would present a high specific protection, but only few would show enough amount to display activity. Therefore, the highest values should be found when a peak in the extraction of one or various antioxidant compounds, with a high specific protection, is produced. In conclusion, a robust system of responses in the RSM experimental design is required to evaluate rigorously the extraction effectiveness of the preservative molecules.

Fig. 3 shows joint 3D analysis in terms of the antioxidant capacity response for the performed optimization process. Fig. 3 is divided in four sections, one for each assay tested (ABTS, DPPH, CM and $\beta C M$ ), being each section divided in three parts, one for each of the evaluated techniques (ME, UAE and MAE). Finally, every part contains three figures showing the responses to the three main variables involved $(t, T$ or $P$ and $S$ ). Each of the net surfaces represents the theoretical threedimensional response surface predicted by the second order polynomial model defined in Eq. (6). Key aspects of the responses obtained are discussed next:

- For ME, low values of $S$ generated the highest yields for or all the studied responses, except for DPPH analysis, in which the best responses are obtained with contents between 10 and $40 \%$.

- For MAE, the low $t$ values give rise to higher efficiency results, comparatively with the other two studied techniques. Such result may be related to the peculiarities of this extraction methodology, since the heat and mass gradient transport phenomenon occurs simultaneously. Moreover, another phenomenon called superheating may also occur leading to these higher values. The superheating is responsible for causing a strong absorption of energy by the water molecules present in the matrix, which causes an increase in the temperature inside the cells and, consequently, to an easier rupture, facilitating the extraction of compounds.

- For UAE, most of the optimum responses obtained are close to the center of the experimental design. Such observation can be explained by the $\mathrm{OH}^{+}$species produced during the cavitation process, and due to the presence of the ethanol that inhibits the formation of the radicals, thus preserving compounds integrity and its bioactivity (Soria \& Villamiel, 2010).

Regarding the comparison between the two HAT based assays, the responses obtained for $\mathrm{CM}$ and $\beta \mathrm{CM}$ antioxidant assays provided additional information considering $H$ and $L$ components, which have 


\section{A: JOINT RESPONSE}
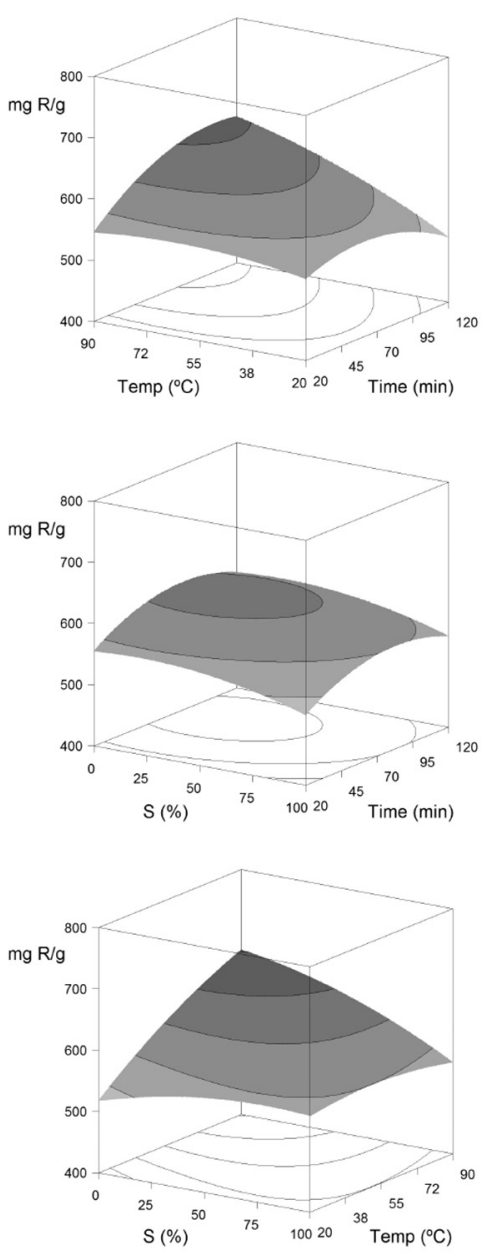

B: ESTATISTICAL DISTRIBUTION

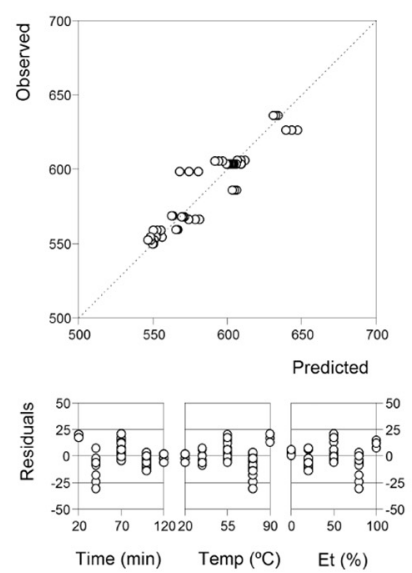

\section{A: JOINT RESPONSE}
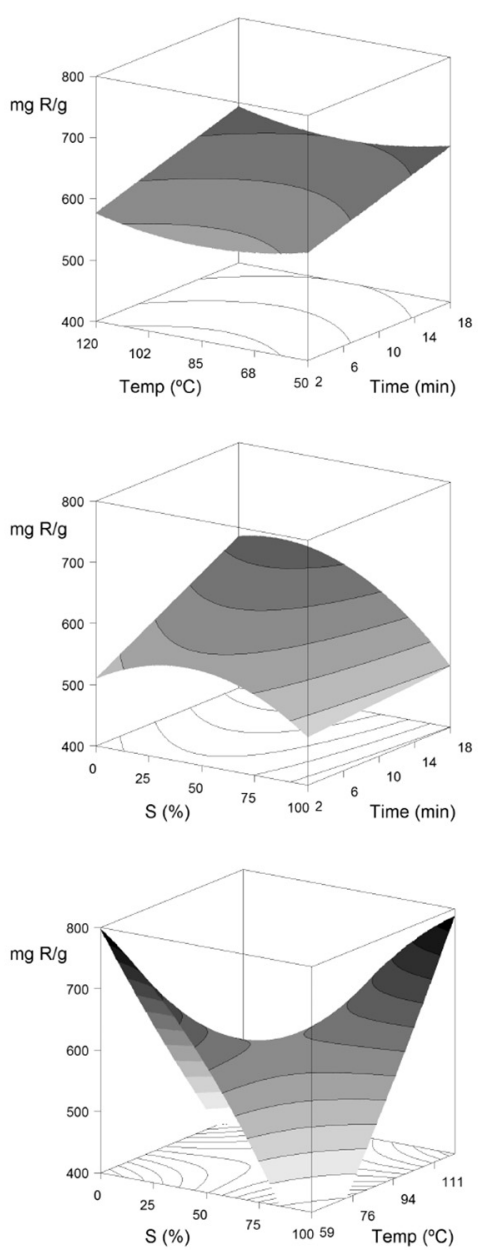

B: ESTATISTICAL DISTRIBUTION

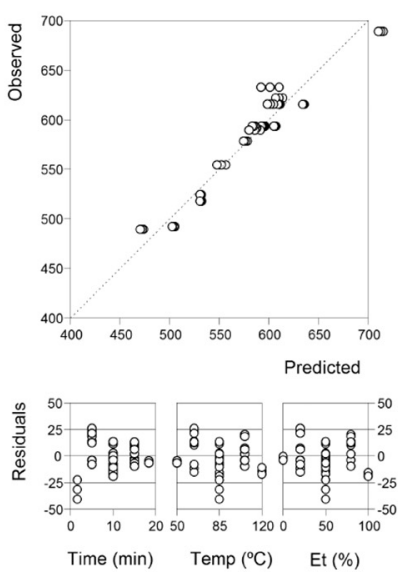

\section{A: JOINT RESPONSE}
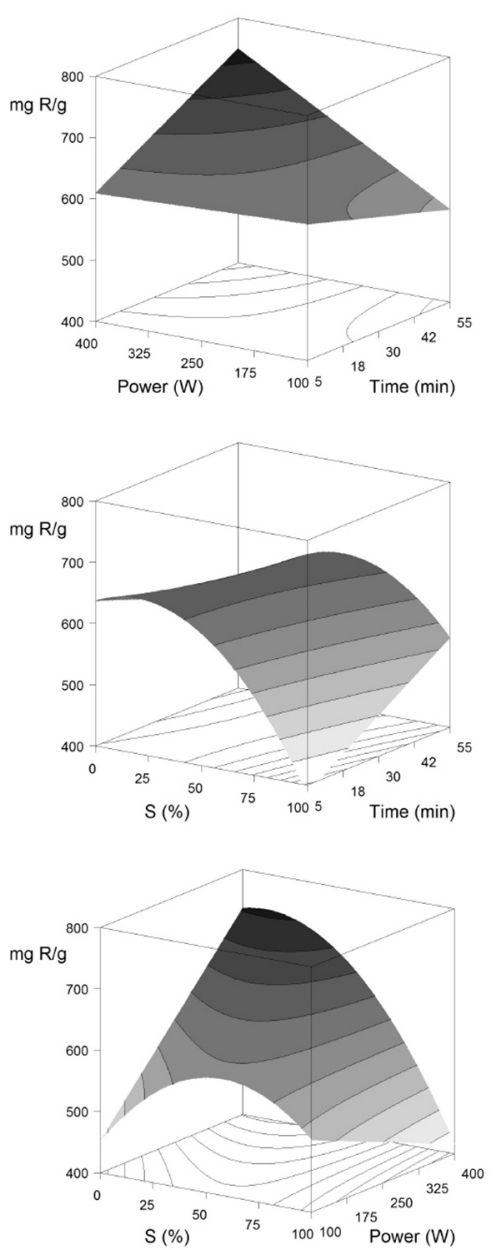

B: ESTATISTICAL DISTRIBUTION

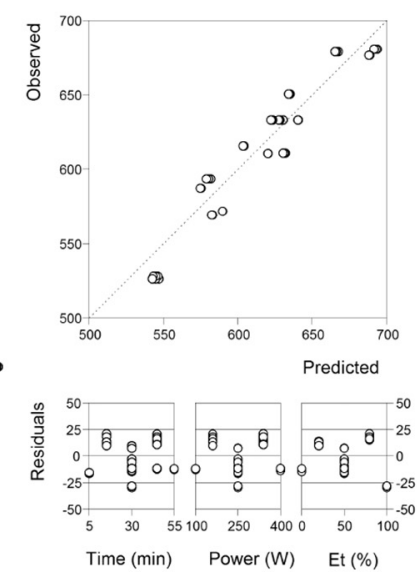

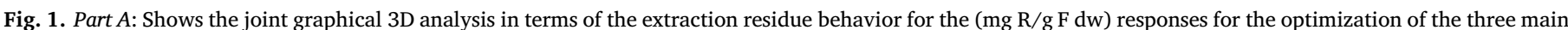

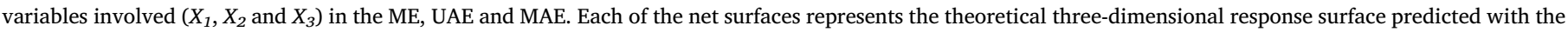

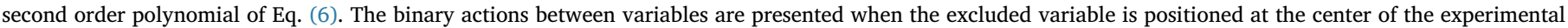

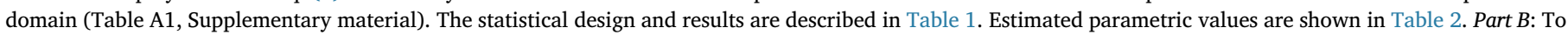

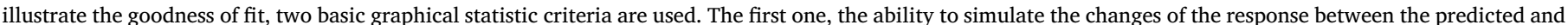

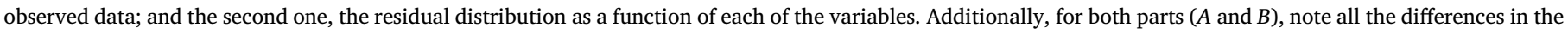
axes scales. 
TS

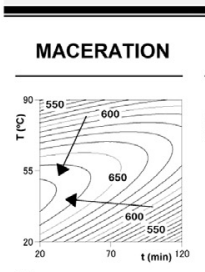

(t)

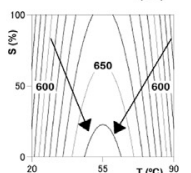

\section{MICROWAVE}
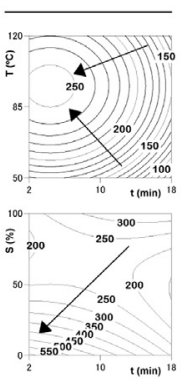

$\frac{8}{5} \underbrace{400}_{250} \underbrace{100}_{200}$

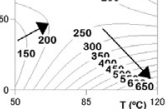

\section{ULTRASOUND}
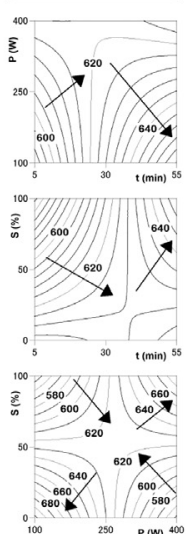

TPC
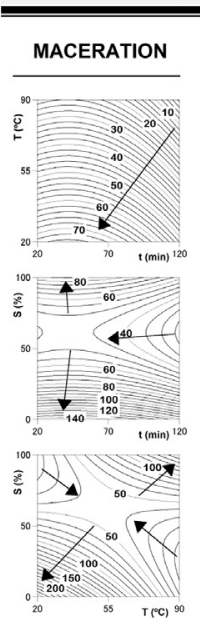
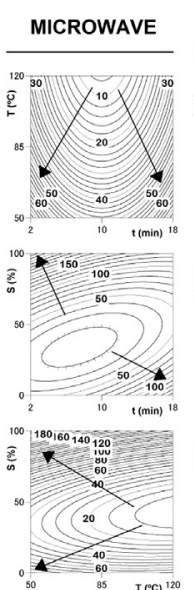

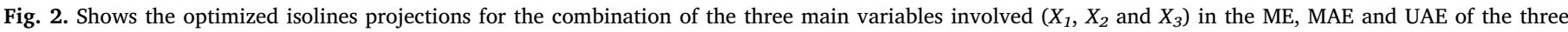

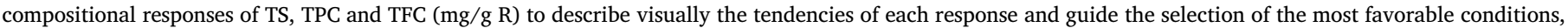

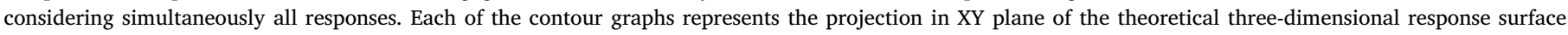

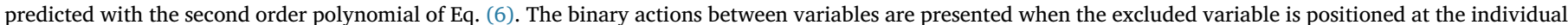
center of the experimental domain (Table A1). The statistical design and results are described in Table 1 . Estimated parametric values are shown in Table 2.
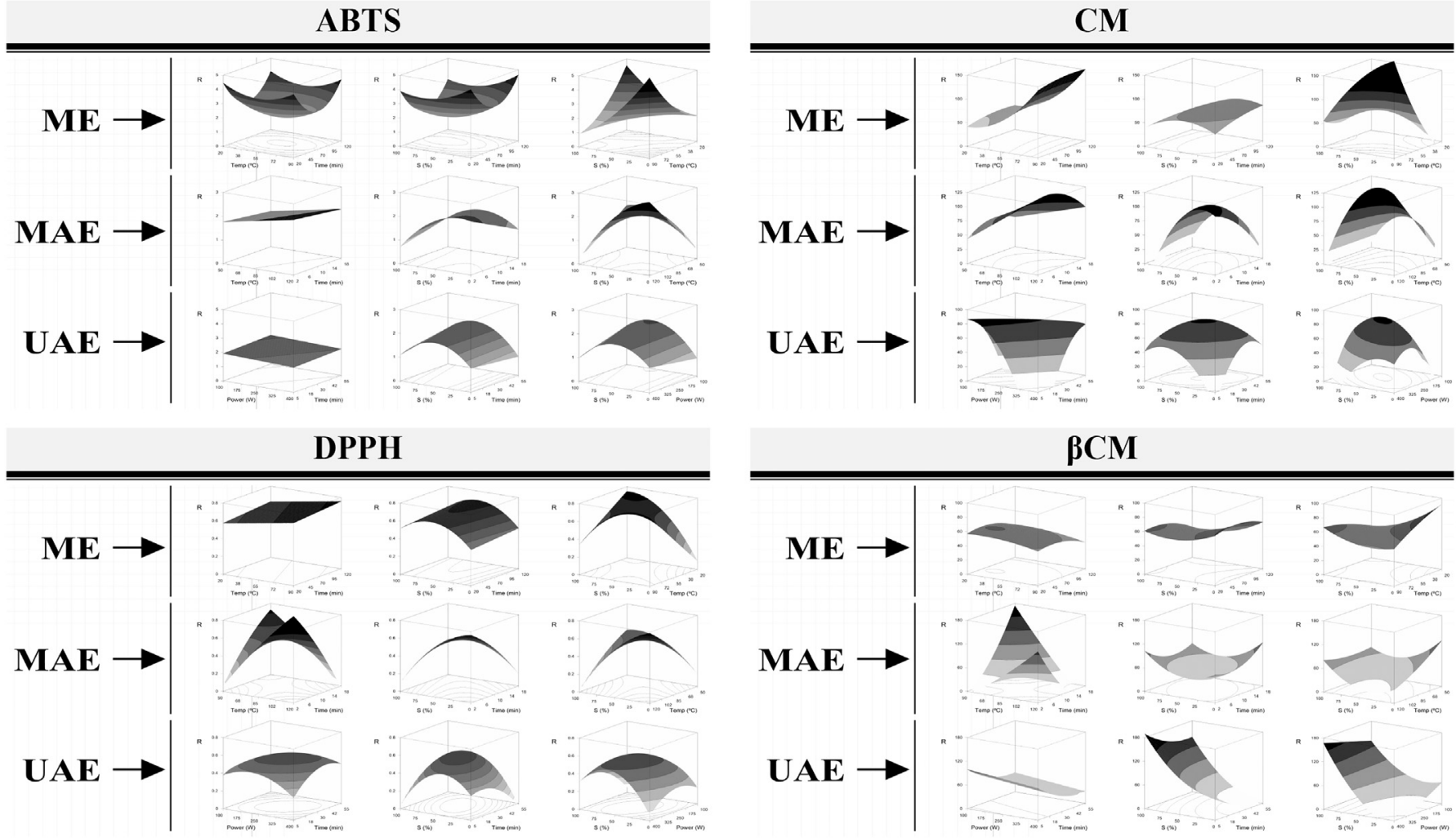

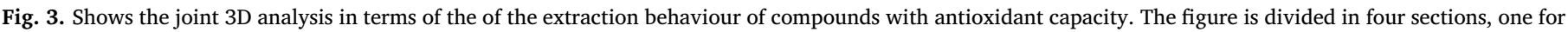

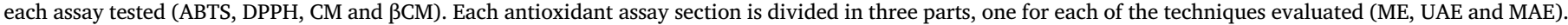

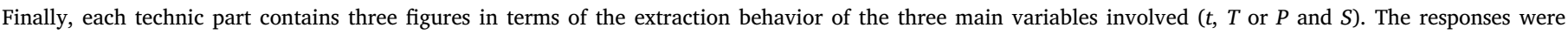

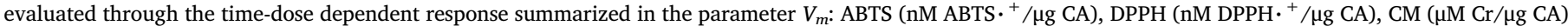

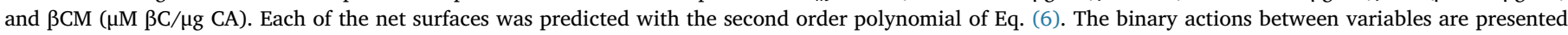

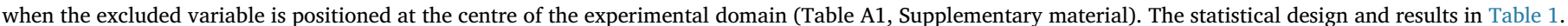
Estimated parametric values are shown in Table 2. 
variable degrees of polarity. In Fig. 3 it can be seen how the patterns of the surface responses generated, behave in opposite direction as a function of the $S$ variable. When using hydroethanol mixtures as the solvent, the extracted antioxidant compounds are favored by the polarity of the solvent used. In consequence, it is reasonable that antioxidant compounds soluble in water $(H$, such as glutathione and phenolic compounds) or in lipids ( $L$, such as $\alpha$-tocopherol and ubiquinol) are extracted as a function of the $S$ variable. Thus, the polarity of the extracts is related with the polarity of the used solvent mixtures. This fact is in accordance with the data reported previously (Prieto et al., 2013; Zhang \& Omaye, 2001), in which antioxidants with a clear $H$ and $L$ character can cause the opposite effect when applied in a reverse environment (i.e. ascorbic acid can initiate lipid oxidation in conjunction with metal cations).

\subsection{Numerical optimal conditions that maximize the response criteria assessed individually, relatively and globally}

By performing a simplex procedure (considering restrictions to the experimental ranges) the desired target objectives are predicted, as well as the response values produced. The optimized variable conditions that lead to maximized response values are presented in Table 3 . The table is organized in three parts: (A) the optimal individual conditions that maximize each response criteria for each used technique; (B) the relative optimal conditions that maximize the values for the composition (R, TS, TPC and TFC) and the antioxidant activity (ABTS, DPPH, CM and $\beta \mathrm{CM}$ ) for each used technique; and (C) the optimal global conditions that maximize the response criteria values for each technique.

For the ideal individual response presented in part A of Table 3 the following general optimal solutions were found:

- For $\mathrm{R}$ response, the best solution is provided by MAE $\left(18.4 \pm 0.9 \mathrm{~min}, 50.1 \pm 6.4{ }^{\circ} \mathrm{C}\right.$ and $0.0 \pm 1.2 \%$ of $\mathrm{S}$ producing $806.3 \pm 105.5 \mathrm{mg} \mathrm{R} / \mathrm{gF} \mathrm{dw}$ ), closely followed by UAE. ME give rise to the lowest extraction yields.

- For TS, the ME showed the best solution $(20.0 \pm 3.2 \mathrm{~min}$, $48.9 \pm 5.8^{\circ} \mathrm{C}$ and $0.0 \pm 0.9 \%$ of $S$ producing $719.0 \pm 61.1 \mathrm{mg}$ $\mathrm{TS} / \mathrm{g}$ R). UAE and MAE showed slightly lower values.

- For TPC, the MAE resulted in the higher contents $(41.6 \pm 6.8 \mathrm{~min}$, $20.0 \pm 0.4{ }^{\circ} \mathrm{C}$ and $0.0 \pm 0.2 \%$ of $\mathrm{S}$ producing $215.3 \pm 17.1 \mathrm{mg}$ $\mathrm{GAE} / \mathrm{g} \mathrm{R}$ ), comparatively with the results provided at the optimal conditions for ME and UAE.

- For TFC, the MAE showed the best solution $(1.6 \pm 0.1 \mathrm{~min}$, $120.0 \pm 10.9^{\circ} \mathrm{C} \quad$ and $\quad 0.0 \pm 1.0 \% \quad S \quad$ producing $81.23 \pm 6.34 \mathrm{mg} \mathrm{CE} / \mathrm{g} \mathrm{R}$ ), closely followed ME. UAE resulted in the lowest contents.

- For ABTS, the ME conducted to the optimal solution $\left(120.0 \pm 1.6 \mathrm{~min}, 90.0 \pm 2.9^{\circ} \mathrm{C}\right.$ and $0.0 \pm 2.4 \% S$ obtaining $\left.6.37 \pm 0.80 \mathrm{nM} \mathrm{ABTS} \cdot{ }^{+} / \mu \mathrm{g} \mathrm{R}\right)$. UAE and MAE give rise to much lower values than those produced by ME.

- For DPPH, the MAE was the optimal solution $(1.6 \pm 0.2 \mathrm{~min}$, $120.0 \pm 7.9^{\circ} \mathrm{C}$ and $0.0 \pm 6.0 \% S$ obtaining $1.10 \pm 0.097 \mathrm{nM}$ $\mathrm{DPPH} \cdot{ }^{+} / \mu \mathrm{g}$ R). UAE and ME conducted to much lower values.

- For CM, the ME corresponds to the best solution $(120.0 \pm 7.5 \mathrm{~min}$, $90.0 \pm 0.6{ }^{\circ} \mathrm{C}$ and $0.0 \pm 3.8 \%$ of $S$ obtaining $181.3 \pm 13.0 \mu \mathrm{M}$ $\mathrm{Cr} / \mathrm{mg} \mathrm{R}$ ), closely followed by MAE. UAE gives rise to the lowest scavenging rate for the AAPH radical for the protection of the $\mathrm{Cr}$ substrate.

- For CM, the UAE resulted in the best results $(5.0 \pm 0.7 \mathrm{~min}$, $400.0 \pm 30.6 \mathrm{~W}$ and $100.0 \pm 10.9 \%$ of $\mathrm{S}$ obtaining $193.48 \pm 5.22 \mu \mathrm{M} \beta \mathrm{C} / \mathrm{mg} \mathrm{R})$, closely followed by MAE. ME produced extracts with the lowest scavenging rate for the lipophilic radicals (derived by oxidation change reaction of linoleic acid) for the protection of the $\beta C$ substrate.
For the relative conditions that optimize the values for the compositional and antioxidant content presented in part B of Table 3 the results showed the following general outcomes:

- For the compositional content, the best extraction system was ME at $67.5 \pm 2.1 \mathrm{~min}, 90.0 \pm 13.3^{\circ} \mathrm{C}$ and $0.0 \pm 1.3 \%$ of $\mathrm{S}$ producing $646.9 \pm 124.3 \mathrm{mg} \quad \mathrm{R} / \mathrm{g} \mathrm{F} \quad \mathrm{dw}, \quad 586.4 \pm 8.7 \mathrm{mg} / \mathrm{g} \quad \mathrm{R}$ of $\mathrm{TS}$, $69.22 \pm 1.62 \mathrm{mg} \mathrm{GAE} / \mathrm{g} \mathrm{R}$ and $73.61 \pm 0.69 \mathrm{mg} \mathrm{CE} / \mathrm{g} \mathrm{R}$ in terms of the response criteria of R, TS, TPC and TFC, respectively. The relative results provided by UAE were closely related to those produced by ME. Although MAE showed high individual response values, when conditions were optimized in relative terms to all other compositional responses, the results showed much lower values than those achieved with the other techniques.

- For the antioxidant capability, the extraction system conducting to the best results was MAE at $1.6 \pm 0.3 \mathrm{~min}, 120.0 \pm 20.9^{\circ} \mathrm{C}$ and $0.0 \pm 3.4 \%$ of $S$ obtaining rates activities of $3.08 \pm 0.06 \mathrm{nM}$ ABTS $\cdot{ }^{+} / \mu \mathrm{g} \mathrm{R}, 1.102 \pm 0.016 \mathrm{nM} \mathrm{DPPH} \cdot{ }^{+} / \mu \mathrm{g} \mathrm{R}, 160.1 \pm 10.3 \mu \mathrm{M} \mathrm{Cr} /$ $\mathrm{mg} \mathrm{R}$ and $92.92 \pm 16.80 \mu \mathrm{M} \beta \mathrm{C} / \mathrm{mg} \mathrm{R}$ in terms of the response criteria to ABTS, DPPH, $C M$ and $\beta C M$, respectively. The relative results provided by ME were comparable to those produced by MAE. UAE showed much lower rate values than those displayed by the other extraction techniques.

Finally, part $\mathrm{C}$ of Table 3 shows the optimized variable conditions producing a global maximum value for all response criteria, for both compositional and antioxidant potential analysis. Shorter times were found with MAE technique considering compositional requirements and antioxidant compounds; whereas for UAE and ME longer extraction times were needed. In conclusion, MAE was the most efficient extraction procedure followed by ME and UAE. For antioxidant capacity, the ME method generated the best responses with ABTS and CM assays, whereas for DPPH and $\beta \mathrm{CM}$ assays MAE was the best technique. In general, ME (120.0 $\pm 16.5 \mathrm{~min}, 90.0 \pm 10.5^{\circ} \mathrm{C}$ and $0.0 \pm 3.8 \%$ of $\left.\mathrm{S}\right)$ produced slightly better results than MAE $(1.6 \pm 0.1 \mathrm{~min}$, $120.0 \pm 2,7^{\circ} \mathrm{C}$ and $0.0 \pm 0.5 \%$ of $\mathrm{S}$ ) and those techniques showed better results than those obtained with UAE $(27.3 \pm 2.6$, $P=235.8 \pm 36.8 \mathrm{~W}$ and $60.8 \pm 0.1 \%$ of $\mathrm{S})$. Under these global conditions, the ME system resulted in compositional parameters of $646.1 \pm 91.6 \mathrm{mg} \quad \mathrm{R} / \mathrm{g} \quad$ of $\mathrm{F} \quad \mathrm{dw}, \quad 535.3 \pm 37.7 \mathrm{mg} \quad \mathrm{TS} / \mathrm{g} \quad \mathrm{R}$, $48.90 \pm 4.0 \mathrm{mg} \mathrm{GAE} / \mathrm{g} \mathrm{R}$ and $76.82 \pm 4.1 \mathrm{mg} \mathrm{CE} / \mathrm{g} \mathrm{R}$ and for the antioxidant potential of $6.38 \pm 0.82 \mathrm{nM} \quad \mathrm{ABTS} \cdot{ }^{+} / \mu \mathrm{g} \quad \mathrm{R}$, $0.658 \pm 0.004 \mathrm{nM} \mathrm{DPPH} \cdot{ }^{+} / \mu \mathrm{g} R, 181.5 \pm 3.7 \mu \mathrm{M} \mathrm{Cr} / \mathrm{mg} \mathrm{R}$ and $50.37 \pm 3.55 \mu \mathrm{M} \beta \mathrm{C} / \mathrm{mg}$ R.

Fig. 4 shows the individual responses for each criterion as a function of all the assessed variables, with the variation of the three studied variables $(t, T$ or $P, S)$ for each extraction method. The dots presented alongside each line highlight the location of the optimum value (Table 3 part C). The lines and dots are generated by the theoretical second order polynomial models of Eq. (6) using the parametric values are show in Table 2. The binary actions between variables are presented when the excluded variable is positioned at the individual optimum of the experimental domain (Table A1).

\subsection{Comparative performance of the antioxidant extract from A. unedo fruits with commercial food antioxidants}

Commercial antioxidants, such as BHA and BHT, are very often used as additives for preventing and reducing oxidative changes in food. Several authors have pointed out the potential risk associated with the use of synthetic antioxidants (Hocman, 1988; Ito, Hirose, Fukushima, \& Tsuda, 1986; Moch, 1986). However, due to the limitation on the use of synthetic antioxidants and enhanced public awareness of health issues, there is an increasing need to develop and use health-promoting natural 
Table 3

Variable conditions in natural values that lead to optimal response values for RSM using of the extracting techniques (ME, UAE and MAE) for all response values.

\begin{tabular}{|c|c|c|c|c|c|c|c|}
\hline \multirow[t]{2}{*}{ Criteria } & & & \multicolumn{3}{|c|}{ Optimal variable conditions } & \multirow[t]{2}{*}{ Optimum response } & \\
\hline & & & $X_{1}: t(\min )$ & $X_{2}: T\left({ }^{\circ} \mathrm{C}\right)$ or $\mathrm{P}(\mathrm{W})$ & $X_{3}: S(\%)$ & & \\
\hline \multicolumn{8}{|c|}{ A) Individual optimal variable conditions } \\
\hline \multirow[t]{8}{*}{ Maceration extraction (ME) } & Compositional analysis & $R$ & $93.2 \pm 16.2$ & $90.0 \pm 3.1$ & $0.0 \pm 1.3$ & $655.9 \pm 7.2$ & $m g R / g F d w$ \\
\hline & & TS & $20.0 \pm 3.2$ & $48.9 \pm 5.8$ & $0.0 \pm 0.9$ & $719.0 \pm 61.1$ & $m g / g R$ \\
\hline & & $T P C$ & $41.6 \pm 6.8$ & $20.1 \pm 0.4$ & $0.0 \pm 0.2$ & $215.3 \pm 17.6$ & $m g / g R$ \\
\hline & & TFC & $120.0 \pm 21.1$ & $90.0 \pm 15.1$ & $13.0 \pm 0.5$ & $77.80 \pm 15.16$ & $m g / g R$ \\
\hline & Antioxidant analysis & ABTS & $120.0 \pm 1.6$ & $90.0 \pm 2.9$ & $0.0 \pm 2.4$ & $6.37 \pm 0.80$ & $n M$ ABTS ${ }^{+} / \mu g R$ \\
\hline & & $D P P H$ & $120.0 \pm 21.5$ & $90.0 \pm 3.7$ & $40.2 \pm 1.0$ & $0.767 \pm 0.112$ & $n M D P P H \cdot{ }^{+} / \mu g R$ \\
\hline & & $C M$ & $120.0 \pm 7.5$ & $90.0 \pm 0.6$ & $0.0 \pm 3.8$ & $181.3 \pm 13.0$ & $\mu M C r / m g R$ \\
\hline & & $\beta C M$ & $60.6 \pm 10.0$ & $37.0 \pm 4.7$ & $0.0 \pm 0.2$ & $80.73 \pm 1.00$ & $\mu M \beta C / m g R$ \\
\hline \multirow[t]{8}{*}{ Microwave assisted extraction (MAE) } & Compositional analysis & $R$ & $18.4 \pm 0.9$ & $50.1 \pm 6.4$ & $0.0 \pm 1.2$ & $806.3 \pm 105.5$ & $m g R / g F d w$ \\
\hline & & TS & $1.6 \pm 0.0$ & $120.0 \pm 11.5$ & $0.0 \pm 2.2$ & $713.9 \pm 21.1$ & $m g / g R$ \\
\hline & & $T P C$ & $18.4 \pm 2.6$ & $50.1 \pm 3.2$ & $0.0 \pm 2.3$ & $164.5 \pm 0.3$ & $m g / g R$ \\
\hline & & $T F C$ & $1.6 \pm 0.1$ & $120.0 \pm 10.9$ & $0.0 \pm 1.0$ & $81.23 \pm 6.34$ & $m g / g R$ \\
\hline & Antioxidant analysis & ABTS & $1.6 \pm 0.2$ & $120.0 \pm 8.0$ & $0.0 \pm 1.4$ & $3.08 \pm 0.22$ & $n M$ ABTS $.^{+} / \mu g R$ \\
\hline & & $D P P H$ & $1.6 \pm 0.2$ & $120.0 \pm 7.9$ & $0.0 \pm 6.0$ & $1.101 \pm 0.097$ & $n M D P P H \cdot{ }^{+} / \mu g R$ \\
\hline & & $C M$ & $1.6 \pm 0.0$ & $120.0 \pm 5.7$ & $10.3 \pm 3.1$ & $162.4 \pm 25.0$ & $\mu M C r / m g R$ \\
\hline & & $\beta C M$ & $18.4 \pm 0.4$ & $50.1 \pm 7.3$ & $0.0 \pm 1.5$ & $191.10 \pm 35.28$ & $\mu M \beta C / m g R$ \\
\hline \multirow[t]{8}{*}{ Ultrasound assisted extraction (UAE) } & Compositional analysis & $R$ & $55.0 \pm 8.5$ & $400.0 \pm 26.9$ & $37.8 \pm 17.8$ & $728.9 \pm 128.6$ & $m g R / g F d w$ \\
\hline & & TS & $43.7 \pm 4.3$ & $100.0 \pm 19.0$ & $0.0 \pm 2.1$ & $674.9 \pm 119.3$ & $m g / g R$ \\
\hline & & $T P C$ & $5.0 \pm 0.9$ & $400.0 \pm 33.5$ & $100.0 \pm 11.5$ & $163.1 \pm 15.9$ & $m g / g R$ \\
\hline & & $T F C$ & $30.0 \pm 3.7$ & $250.0 \pm 2.3$ & $50.0 \pm 4.7$ & $30.22 \pm 5.00$ & $m g / g R$ \\
\hline & Antioxidant analysis & ABTS & $55.0 \pm 9.9$ & $100.0 \pm 1.3$ & $65.6 \pm 0.6$ & $2.11 \pm 0.16$ & $n M$ ABTS ${ }^{+} / \mu g R$ \\
\hline & & $D P P H$ & $31.8 \pm 2.3$ & $271.3 \pm 14.6$ & $54.2 \pm 2.2$ & $0.590 \pm 0.034$ & $n M D P P H \cdot{ }^{+} / \mu g R$ \\
\hline & & $C M$ & $26.5 \pm 0.5$ & $223.8 \pm 0.4$ & $55.9 \pm 5.7$ & $82.6 \pm 1.3$ & $\mu \mathrm{MCr} / \mathrm{mg} R$ \\
\hline & & $\beta C M$ & $5.0 \pm 0.7$ & $400.0 \pm 30.6$ & $100.0 \pm 10.9$ & $193.48 \pm 5.22$ & $\mu M \beta C / m g R$ \\
\hline \multicolumn{8}{|c|}{ B) Relative global optimal variable conditions } \\
\hline \multirow[t]{8}{*}{ Maceration extraction (ME) } & Compositional analysis & $R$ & $67.5 \pm 2.1$ & $90.0 \pm 13.3$ & $0.0 \pm 1.3$ & $646.9 \pm 124.3$ & $m g R / g F d w$ \\
\hline & & TS & & & & $586.4 \pm 8.7$ & $m g / g R$ \\
\hline & & $T P C$ & & & & $69.22 \pm 1.62$ & $m g / g R$ \\
\hline & & TFC & & & & $73.61 \pm 0.69$ & $m g / g R$ \\
\hline & Antioxidant analysis & ABTS & $120.0 \pm 13.7$ & $90.0 \pm 10.5$ & $0.0 \pm 3.8$ & $6.38 \pm 0.54$ & $n M$ ABTS ${ }^{+} / \mu g R$ \\
\hline & & $D P P H$ & & & & $0.658 \pm 0.025$ & $n M D P P H \cdot{ }^{+} / \mu g R$ \\
\hline & & $C M$ & & & & $181.5 \pm 25.6$ & $\mu M C r / m g R$ \\
\hline & & $\beta C M$ & & & & $50.37 \pm 5.18$ & $\mu M \beta C / m g R$ \\
\hline \multirow[t]{8}{*}{ Microwave assisted extraction (MAE) } & Compositional analysis & $R$ & $1.6 \pm 0.2$ & $120.0 \pm 18.6$ & $0.0 \pm 0.2$ & $394.2 \pm 36.0$ & $m g R / g F d w$ \\
\hline & & TS & & & & $714.7 \pm 129.8$ & $m g / g R$ \\
\hline & & $T P C$ & & & & $38.78 \pm 3.52$ & $m g / g R$ \\
\hline & & $T F C$ & & & & $81.30 \pm 12.86$ & $m g / g R$ \\
\hline & Antioxidant analysis & ABTS & $1.6 \pm 0.3$ & $120.0 \pm 20.9$ & $0.0 \pm 3.4$ & $3.08 \pm 0.06$ & $n M$ ABTS ${ }^{+} / \mu g R$ \\
\hline & & $D P P H$ & & & & $1.102 \pm 0.016$ & $n M D P P H \cdot{ }^{+} / \mu g R$ \\
\hline & & $C M$ & & & & $160.1 \pm 10.3$ & $\mu M C r / m g R$ \\
\hline & & $\beta C M$ & & & & $92.92 \pm 16.80$ & $\mu M \beta C / m g R$ \\
\hline \multirow[t]{8}{*}{ Ultrasound assisted extraction (UAE) } & Compositional analysis & $R$ & $28.6 \pm 2.1$ & $246.7 \pm 37.2$ & $58.8 \pm 11.1$ & $616.4 \pm 12.3$ & $m g R / g F d w$ \\
\hline & & TS & & & & $620.9 \pm 64.2$ & $m g / g R$ \\
\hline & & $T P C$ & & & & $29.30 \pm 4.20$ & $m g / g R$ \\
\hline & & $T F C$ & & & & $29.49 \pm 0.72$ & $m g / g R$ \\
\hline & Antioxidant analysis & ABTS & $25.7 \pm 4.7$ & $224.5 \pm 27.3$ & $61.9 \pm 9.5$ & $1.90 \pm 0.21$ & $n M$ ABTS ${ }^{+} / \mu g R$ \\
\hline & & $D P P H$ & & & & $0.558 \pm 0.048$ & $n M D P P H \cdot{ }^{+} / \mu g R$ \\
\hline & & $C M$ & & & & $82.1 \pm 3.3$ & $\mu M C r / m g R$ \\
\hline & & $\beta C M$ & & & & $73.15 \pm 3.22$ & $\mu M \beta C / m g R$ \\
\hline C) Global optimal variable conditions & & & & & & & \\
\hline Maceration extraction (ME) & Compositional analysis & $R$ & $120.0 \pm 16.5$ & $90.0 \pm 15.0$ & $0.0 \pm 2.4$ & $646.1 \pm 91.6$ & $m g R / g F d w$ \\
\hline & & $T S$ & & & & $535.3 \pm 37.7$ & $m g / g R$ \\
\hline & & $T P C$ & & & & $48.90 \pm 4.01$ & $m g / g R$ \\
\hline & & TFC & & & & $76.82 \pm 4.13$ & $m g / g R$ \\
\hline & Antioxidant analysis & ABTS & & & & $6.38 \pm 0.82$ & $n M$ ABTS $.^{+} / \mu g R$ \\
\hline & & $D P P H$ & & & & $0.658 \pm 0.004$ & $n M D P P H \cdot{ }^{+} / \mu g R$ \\
\hline & & $C M$ & & & & $181.5 \pm 3.7$ & $\mu M C r / m g R$ \\
\hline & & $\beta C M$ & & & & $50.37 \pm 3.55$ & $\mu M \beta C / m g R$ \\
\hline Microwave assisted extraction (MAE) & Compositional analysis & $R$ & $1.6 \pm 0.1$ & $120.0 \pm 2.7$ & $0.0 \pm 0.5$ & $394.2 \pm 36.5$ & $m g R / g F d w$ \\
\hline & & TS & & & & $714.7 \pm 55.3$ & $m g / g R$ \\
\hline & & $T P C$ & & & & $38.78 \pm 4.41$ & $m g / g R$ \\
\hline & & $T F C$ & & & & $81.30 \pm 11.38$ & $m g / g R$ \\
\hline & Antioxidant analysis & ABTS & & & & $3.08 \pm 0.50$ & $n M$ ABTS $\cdot^{+} / \mu g R$ \\
\hline & & $D P P H$ & & & & $1.102 \pm 0.058$ & $n M D P P H \cdot{ }^{+} / \mu g R$ \\
\hline & & $C M$ & & & & $160.1 \pm 19.9$ & $\mu M C r / m g R$ \\
\hline & & $\beta C M$ & & & & $92.92 \pm 13.92$ & $\mu M \beta C / m g R$ \\
\hline
\end{tabular}


Table 3 (continued)

\begin{tabular}{|c|c|c|c|c|c|c|c|}
\hline \multirow[t]{2}{*}{ Criteria } & & & \multicolumn{3}{|c|}{ Optimal variable conditions } & \multirow[t]{2}{*}{ Optimum response } & \\
\hline & & & $X_{1}: t(\min )$ & $X_{2}: T\left({ }^{\circ} \mathrm{C}\right)$ or $\mathrm{P}(\mathrm{W})$ & $X_{3}: S(\%)$ & & \\
\hline \multirow[t]{8}{*}{ Ultrasound assisted extraction (UAE) } & Compositional analysis & $R$ & $27.3 \pm 2.6$ & $235.8 \pm 36.8$ & $60.8 \pm 0.1$ & $608.4 \pm 101.1$ & $m g R / g F d w$ \\
\hline & & TS & & & & $619.0 \pm 10.8$ & $m g / g R$ \\
\hline & & $T P C$ & & & & $33.48 \pm 2.59$ & $m g / g R$ \\
\hline & & $T F C$ & & & & $29.00 \pm 5.65$ & $m g / g R$ \\
\hline & Antioxidant analysis & ABTS & & & & $1.90 \pm 0.30$ & $n M$ ABTS ${ }^{+} / \mu g R$ \\
\hline & & $D P P H$ & & & & $0.570 \pm 0.050$ & $n M D P P H \cdot{ }^{+} / \mu g R$ \\
\hline & & $C M$ & & & & $81.8 \pm 0.3$ & $\mu M C r / m g R$ \\
\hline & & $\beta C M$ & & & & $68.95 \pm 6.14$ & $\mu M \beta C / m g R$ \\
\hline
\end{tabular}

COMPOSITIONAL ANALYSIS

MACERATION

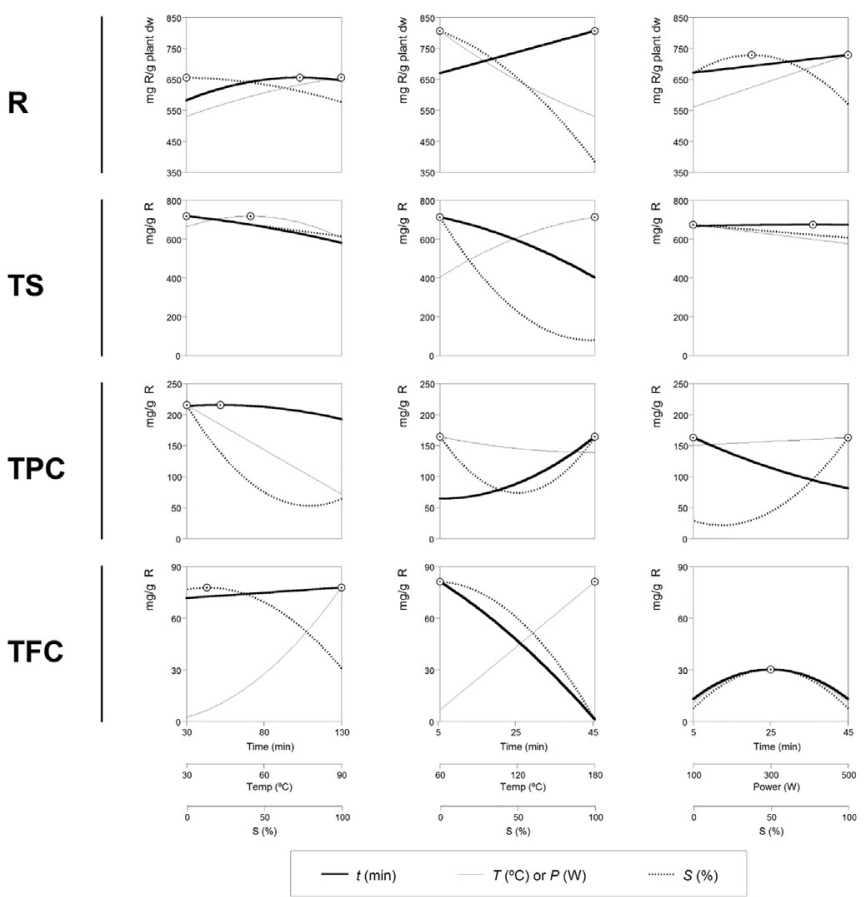

ANTIOXIDANT ANALYSIS

MACERATION MICROWAVE ULTRASOUND

ABTS
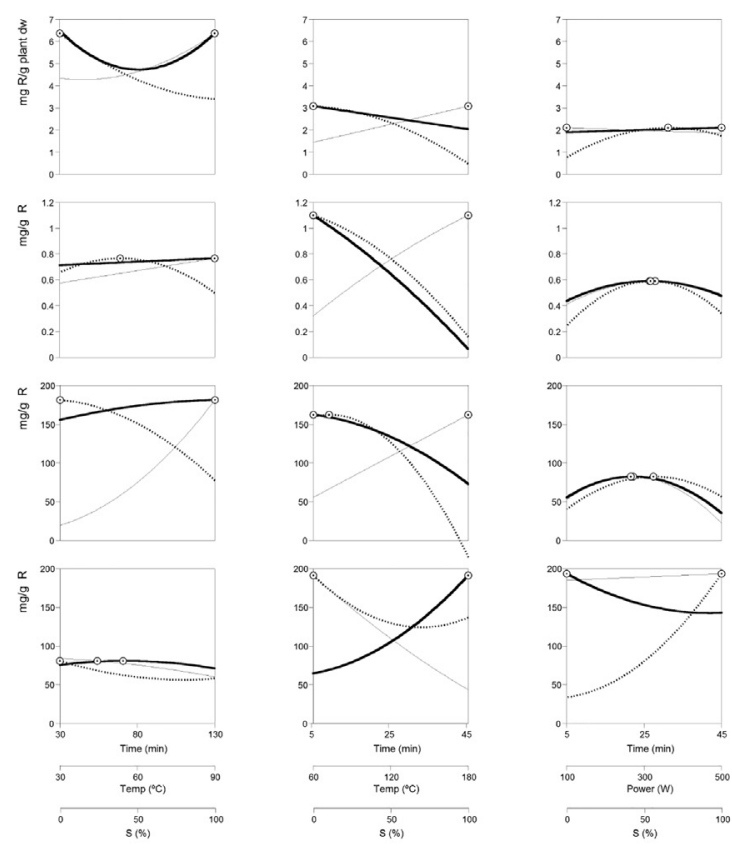

CM

DPPH

$\beta \mathrm{CM}$
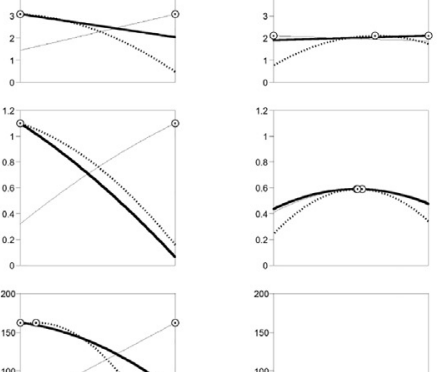

200

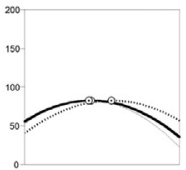$$
20
$$
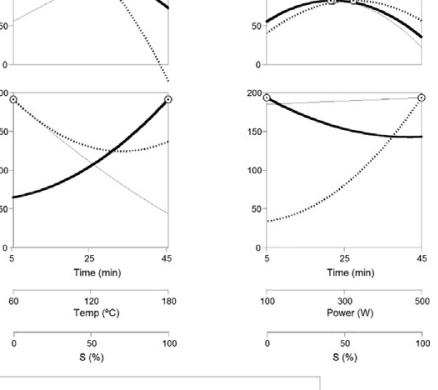

$-t(\min )$

$T\left({ }^{\circ} \mathrm{C}\right)$ or $P(\mathrm{~W})$

..... $s(\%)$

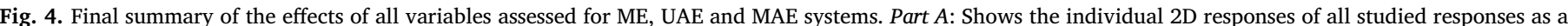

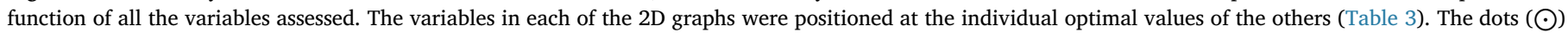

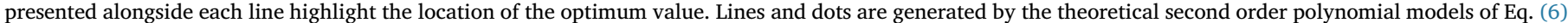
using the estimated parametric values are shown in Table 2.

antioxidant ingredients in foods (Carocho, Morales, \& Ferreira, 2015). In this context, different antioxidant compounds derived from natural sources have been used as food additives to prevent oxidative deterioration processes (Marcio Carocho et al., 2014). In this study, the antioxidant activity of the produced extracts was compared with the activity of some commercial antioxidants (CA) commonly used in the food industry. Table 4 shows the estimated numerical values of the parameters ( $K, V_{m}$ and $a$ ) of Eq. (4), after fitting the concentration-response values obtained for ABTS, DPPH, $\beta \mathrm{CM}$ and $\mathrm{CM}$ antioxidant assays of the selected $C A$. The equivalence is computed in terms of the numerical time-dose dependent parameter $V_{m}$ and displayed in times less effective that the optimal values of the extract samples regarding the commercial antioxidant.

The antioxidant capacity of $A$. unedo fruits extract was lower than the one of the chosen commercial food antioxidants. However, the developed ingredient presented a potential to be used in the fortification and functionalization of food products. Despite presenting a lower antioxidant activity, in comparison with the evaluated commercial antioxidants, it is important to note that these fruit extracts are composed of different biomolecules while the commercial antioxidants are isolated pure compounds.

\section{Conclusions}

The obtainment of an extract rich in different bio-compounds from A. unedo using three methodologies (ME, MAE and UAE techniques) was optimized by RSM considering the significant variables for each process $(t, T$ or $P$ and $S$ ). The response criteria used were based in terms of the composition (extraction yield of R and the content in TS, TPC and TFC) and in terms of its preservative potential (antioxidant methods of 
Table 4

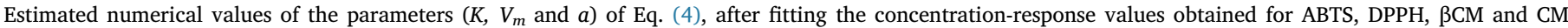

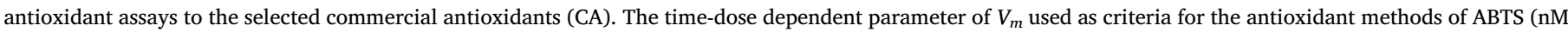

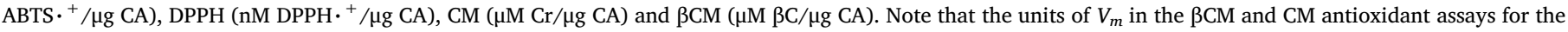

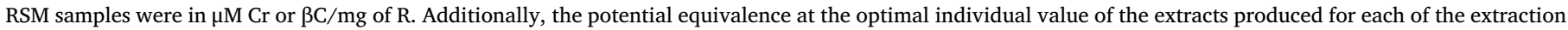

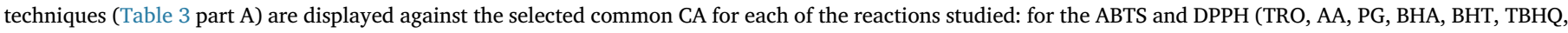

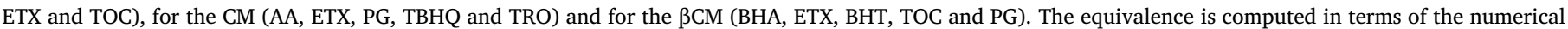
parameter $V_{m}$ and displays in times less effective that the optimal values of the extract samples are regarding the commercial antioxidant.

\begin{tabular}{|c|c|c|c|c|c|c|c|c|c|c|}
\hline \multirow[t]{2}{*}{ CA } & \multicolumn{6}{|c|}{ Parameters from Eq. (4) } & \multirow{2}{*}{$\begin{array}{l}\text { Statistics } \\
R^{2} a d j\end{array}$} & \multicolumn{3}{|c|}{ Potential equivalence } \\
\hline & $K$ & & $V_{m}$ & & $a$ & & & $M E$ & $M A E$ & $U A E$ \\
\hline \multicolumn{11}{|c|}{ DPPH assay } \\
\hline TRO & 29.92 & \pm 2.4 & 30.39 & \pm 1.1 & 1.92 & \pm 9.6 & 0.9997 & 39.6 & 27.6 & 51.5 \\
\hline$A A$ & 29.64 & \pm 1.6 & 40.25 & \pm 1.4 & 3.14 & \pm 7.6 & 0.9997 & 52.5 & 36.6 & 68.2 \\
\hline$P G$ & 29.83 & \pm 1.7 & 60.81 & \pm 1.3 & 1.48 & \pm 5.5 & 0.9991 & 79.3 & 55.2 & 103.1 \\
\hline$B H A$ & 27.92 & \pm 3.2 & 20.37 & \pm 2.3 & 1.18 & \pm 14.1 & 0.9985 & 26.6 & 18.5 & 34.5 \\
\hline BHT & 30.10 & \pm 1.7 & 4.65 & \pm 1.0 & 1.39 & \pm 5.1 & 0.9985 & 6.1 & 4.2 & 7.9 \\
\hline$T B H Q$ & 29.96 & \pm 1.7 & 40.41 & \pm 1.8 & 1.80 & \pm 6.0 & 0.9998 & 52.7 & 36.7 & 68.5 \\
\hline ETX & 29.68 & \pm 1.0 & 20.70 & \pm 0.5 & 1.69 & \pm 2.5 & 0.9995 & 27.0 & 18.8 & 35.1 \\
\hline TOC & 29.64 & \pm 3.3 & 20.31 & \pm 0.7 & 1.41 & \pm 8.5 & 0.9994 & 26.5 & 18.4 & 34.4 \\
\hline \multicolumn{11}{|c|}{ ABTS assay } \\
\hline TRO & 14.73 & \pm 3.8 & 45.02 & \pm 1.6 & 1.39 & \pm 0.2 & 0.9988 & 7.1 & 14.6 & 21.3 \\
\hline$A A$ & 14.53 & \pm 2.8 & 14.38 & \pm 2.6 & 1.66 & \pm 0.1 & 0.9997 & 2.3 & 4.7 & 6.8 \\
\hline$P G$ & 15.93 & \pm 3.3 & 93.26 & \pm 1.7 & 1.63 & \pm 0.1 & 0.9993 & 14.6 & 30.3 & 44.2 \\
\hline BHA & 15.00 & \pm 9.1 & 52.74 & \pm 1.7 & 1.26 & \pm 0.1 & 0.9994 & 8.3 & 17.1 & 25.0 \\
\hline BHT & 15.02 & \pm 6.5 & 10.01 & \pm 1.4 & 0.92 & \pm 0.1 & 0.9994 & 1.6 & 3.3 & 4.7 \\
\hline$T B H Q$ & 15.00 & \pm 3.2 & 90.62 & \pm 2.1 & 0.87 & \pm 0.1 & 0.9992 & 14.2 & 29.4 & 42.9 \\
\hline$E T X$ & 15.16 & \pm 2.2 & 58.06 & \pm 1.8 & 1.73 & \pm 0.1 & 0.9996 & 9.1 & 18.9 & 27.5 \\
\hline TOC & 15.01 & \pm 1.8 & 20.21 & \pm 1.7 & 2.67 & \pm 0.1 & 0.9999 & 3.2 & 6.6 & 9.6 \\
\hline \multicolumn{11}{|c|}{$\beta C A$ assay } \\
\hline BHA & 1.00 & \pm 0.1 & 5.419 & \pm 1.1 & 1.04 & \pm 5.6 & 0.9990 & 67.1 & 28.4 & 28.0 \\
\hline ETX & 1.00 & \pm 0.1 & 75.99 & \pm 0.3 & 1.50 & \pm 12.8 & 0.9982 & 941.3 & 397.6 & 392.8 \\
\hline BHT & 1.00 & \pm 0.1 & 0.823 & \pm 0.1 & 1.18 & \pm 5.6 & 0.9950 & 10.2 & 4.3 & 4.3 \\
\hline TOC & 1.00 & \pm 0.1 & 1.122 & \pm 0.3 & 1.32 & \pm 3.1 & 0.9936 & 13.9 & 5.9 & 5.8 \\
\hline$P G$ & 1.00 & \pm 0.1 & 0.047 & \pm 0.01 & 0.50 & \pm 15.2 & 0.9964 & 0.6 & 0.2 & 0.2 \\
\hline \multicolumn{11}{|c|}{ CM assay } \\
\hline$A A$ & 100.00 & \pm 1.0 & 0.177 & \pm 0.01 & 0.81 & \pm 9.7 & 0.9998 & 1.0 & 1.1 & 2.1 \\
\hline ETX & 100.00 & \pm 2.2 & 42.66 & \pm 0.1 & 1.15 & \pm 8.6 & 0.9998 & 235.3 & 262.7 & 516.5 \\
\hline$P G$ & 100.00 & \pm 1.1 & 0.417 & \pm 0.1 & 0.93 & \pm 20.9 & 0.9961 & 2.3 & 2.6 & 5.0 \\
\hline$T B H Q$ & 100.00 & \pm 0.8 & 0.040 & \pm 0.01 & 0.84 & \pm 29.2 & 0.9996 & 0.2 & 0.2 & 0.5 \\
\hline TRO & 100.00 & \pm 0.5 & 0.625 & \pm 0.1 & 1.20 & \pm 12.8 & 0.9992 & 3.4 & 3.8 & 7.6 \\
\hline
\end{tabular}

ABTS, DPPH, CM and $\beta C M)$. For composition, although slight differences among the techniques were found, ME proved to be the best technique, followed by UAE and MAE. For the preservative potential, the extracts obtained by ME method resulted more efficient for the ABTS and CM assays and the ones obtained by MAE showed better results with DPPH and $\beta C M$.

Although the conventional method of ME was found to be a more efficient solution followed by UAE and MAE, the presented results offer alternatives to meet different process and requirements for target objectives, resulting in flexible solutions for industrial purposes. Based on these optimized processing parameters it will be possible to produce food ingredients with different properties according to the intended purpose (with high level of nutrients, increased antioxidant properties, or both). Additionally, the equivalent potential capacity of the $A$. unedo fruit extracts corresponding to the optimal response using ME, MAE and UAE techniques were compared with some commercial antioxidants. Thus, the antioxidant potential of the optimized solutions for the extraction of $A$. unedo fruit was completely understood for its possible industrial application. The equivalences would provide relevant information on the appropriate concentrations of natural products able to replace commercial antioxidants.

\section{Acknowledgements}

The authors thank the Foundation for Science and Technology (FCT, Portugal) and FEDER under Programme PT2020 for financial support to
CIMO (UID/AGR/00690/2013) and L. Barros contract. The authors are also grateful to FEDER-Interreg España-Portugal programme for financial support through the project 0377_Iberphenol_6_E; and to the European Structural and Investment Funds (FEEI) through the Regional Operational Program North 2020, within the scope of Project NORTE01-0145-FEDER-023289: DeCodE. To POCI-01-0145-FEDER-006984 (LA LSRE-LCM), funded by FEDER, through POCI-COMPETE2020 and FCT. To Xunta de Galicia for financial support for the post-doctoral researcher of M.A. Prieto. B. Albuquerque thanks Celeide Pereira (UTFPR, Brazil) for her master co-supervision. Finally, the authors want to express their gratitude to Araceli Menduiña Santomé (Instituto de Investigacións Mariñas, IIM-CSIC) for her professional work and dedication on the production of the laboratory results.

\section{Appendix A. Supplementary data}

Supplementary data to this article can be found online at https:// doi.org/10.1016/j.foodres.2018.04.061.

\section{References}

Ahmad, M. F., Ashraf, S. A., Ahmad, F. A., Ansari, J. A., \& Siddiquee, M. R. A. (2011). Nutraceutical market and its regulation. American Journal of Food Technology, 6, 342-347.

Albuquerque, B. R., Prieto, M. A., Barreiro, M. F., Rodrigues, A., Curran, T. P., Barros, L., \& Ferreira, I. C. F. R. (2016). Catechin-based extract optimization obtained from Arbutus unedo L. fruits using maceration/microwave/ultrasound extraction 
techniques. Industrial Crops and Products, 95, 404-415.

Arts, M. (2004). A new approach to assess the total antioxidant capacity using the TEAC assay. Food Chemistry, 88(4), 567-570.

Ayaz, F. A., Kucukislamoglu, M., \& Reunanen, M. (2000). Sugar, non-volatile and phenolic acids composition of strawberry tree (Arbutus unedo L. var.ellipsoidea) fruits. Journal of Food Composition and Analysis, 13(2), 171-177.

Baiano, A., Luisa, B., Carmela, T., Contò, F., \& Del Nobile, M. A. (2014). Single and interactive effects of process variables on microwave-assisted. Journal of Food Engineering, 120, 135-145.

Barros, L., Carvalho, A. M., Morais, J. S., \& Ferreira, I. C. F. R. (2010). Strawberry-tree, blackthorn and rose fruits: Detailed characterisation in nutrients and phytochemicals with antioxidant properties. Food Chemistry, 120(1), 247-254.

Belwal, T., Bhatt, I. D., Rawal, R. S., \& Pande, V. (2017). Microwave-assisted extraction (MAE) conditions using polynomial design for improving antioxidant phytochemicals in Berberis asiatica Roxb. ex DC. leaves. Industrial Crops and Products, 95, 393-403.

Bezerra, M. A., Santelli, R. E., Oliveira, E. P., Villar, L. S., Escaleira, E. A., \& Escaleira, L. A. (2008). Response surface methodology (RSM) as a tool for optimization in analytical chemistry. Talanta, 76(5), 965-977.

Bors, W., Michel, C., \& Saran, M. (1984). Inhibition of the bleaching of the carotenoid crocin a rapid test for quantifying antioxidant activity. Biochimica et Biophysica Acta, 796(3), 312-319.

Bursać Kovačević, D., Barba, F. J., Granato, D., Galanakis, C. M., Herceg, Z., DragovićUzelac, V., \& Putnik, P. (2018). Pressurized hot water extraction (PHWE) for the green recovery of bioactive compounds and steviol glycosides from Stevia rebaudiana Bertoni leaves. Food Chemistry, 254(September 2017), 150-157.

Carocho, M., Barreiro, M. F., Morales, P., \& Ferreira, I. C. F. R. (2014). Adding molecules to food, pros and cons: A review on synthetic and natural food additives. Comprehensive Reviews in Food Science and Food Safety, 13(4), 377-399.

Carocho, M., \& Ferreira, I. C. F. R. (2013). A review on antioxidants, prooxidants and related controversy: Natural and synthetic compounds, screening and analysis methodologies and future perspectives. Food and Chemical Toxicology: An International Journal Published for the British Industrial Biological Research Association, 51, 15-25.

Carocho, M., Morales, P., \& Ferreira, I. C. F. R. (2015). Natural food additives: Quo vadis? Trends in Food Science \& Technology, 45, 284-295.

Choi, Y. H., van Spronsen, J., Dai, Y., Verberne, M., Hollmann, F., Arends, I. W. C. E., \& Verpoorte, R. (2011). Are natural deep eutectic solvents the missing link in understanding cellular metabolism and physiology? Plant Physiology, 156, 1701-1705.

Dávalos, A., Gómez-Cordovés, C., \& Bartolomé, B. (2004). Extending applicability of the oxygen radical absorbance capacity (ORAC-fluorescein) assay. Journal of Agricultural and Food Chemistry, 52(1), 48-54.

DuBois, M., Gilles, K. A., Hamilton, J. K., Rebers, P. A., \& Smith, F. (1956). Colorimetric Method for Determination of Sugars and Related Substances. Analytical Chemistry, 28(3), 350-356.

Fattore, M., Montesano, D., Pagano, E., Teta, R., Borrelli, F., Mangoni, A., \& Albrizio, S. (2016). Carotenoid and flavonoid profile and antioxidant activity in "Pomodorino Vesuviano" tomatoes. Journal of Food Composition and Analysis, 53(1238), 61-68.

Ferreira, S. L. C., Bruns, R. E., Ferreira, H. S., Matos, G. D., David, J. M., Brandão, G. C., \& dos Santos, W. N. L. (2007). Box-Behnken design: An alternative for the optimization of analytical methods. Analytica Chimica Acta, 597(2), 179-186.

Galanakis, C. M. (2012). Recovery of high added-value components from food wastes: Conventional, emerging technologies and commercialized applications. Trends in Food Science and Technology, 26, 68-87.

García-Moreno, P. J., Batista, I., Pires, C., Bandarra, N. M., Espejo-Carpio, F. J., Guadix, A., \& Guadix, E. M. (2014). Antioxidant activity of protein hydrolysates obtained from discarded Mediterranean fish species. Food Research International, 65(PC, 469-476.

Ghasemzadeh, A., Jaafar, H. Z. E., Karimi, E., \& Rahmat, A. (2014). Optimization of ultrasound-assisted extraction of flavonoid compounds and their pharmaceutical activity from curry leaf (Murraya koenigii L.) using response surface methodology. BMC Complementary and Alternative Medicine, 14(318), 1-10.

Guimarães, R., Barros, L., Calhelha, R. C., Carvalho, A. M., Queiroz, M. J. R. P., \& Ferreira, I. C. F. R. (2014). Bioactivity of different enriched phenolic extracts of wild fruits from Northeastern Portugal: A comparative study. Plant Foods for Human Nutrition, 69(1), 37-42.

Guimarães, R., Barros, L., Dueñas, M., Carvalho, A. M., Queiroz, M. J. R. P., SantosBuelga, C., \& Ferreira, I. C. F. R. (2013). Characterisation of phenolic compounds in wild fruits from Northeastern Portugal. Food Chemistry, 141, 3721-3730.

Heleno, S. A., Diz, P., Prieto, M. A., Barros, L., Rodrigues, A., Barreiro, M. F., \& Ferreira, I. C. F. R. (2016). Optimization of ultrasound-assisted extraction to obtain mycosterols from Agaricus bisporus L. by response surface methodology and comparison with conventional Soxhlet extraction. Food Chemistry, 197, 1054-1063.

Hocman, G. (1988). Chemoprevention of cancer: Phenolic antioxidants (BHT, BHA). International Journal of Biochemistry, 20, 639-651.

Huang, D., Ou, B., Hampsch-Woodill, M., Flanagan, J., \& Prior, R. (2002). Highthroughput assay of oxygen radical absorbance capacity (ORAC) using a multichannel liquid handling system coupled with a microplate fluorescence reader in 96well format. Journal of Agricultural and Food Chemistry, 50(16), 4437-4444.

Huang, D., Ou, B., Prior, R. L., \& Ronald, L. (2005). The chemistry behind antioxidant capacity assays. Journal of Agricultural and Food Chemestry, 53(6), 1841-1856.

Ito, N., Hirose, M., Fukushima, S., \& Tsuda, H. (1986). Studies on antioxidants: Their carcinogenic and modifying effects on chemical carcinogenesis. Food and Chemical Toxicology, 24, 1071-1082.

Jiménez-Escrig, A., Jiménez-Jiménez, I., Sánchez-Moreno, C., \& Saura-Calixto, F. (2000). Evaluation of free radical scavenging of dietary carotenoids by the stable radical 2,2diphenyl-1-picrylhydrazyl. Journal of the Science of Food and Agriculture, 80(11), $1686-1690$.
Liyana-Pathirana, C., \& Shahidi, F. (2005). Optimization of extraction of phenolic compounds from wheat using response surface methodology. Food Chemistry, 93(1), 47-56.

Marco, G. J. (1968). A rapid method for evaluation of antioxidants. Journal of the American Oil Chemists' Society, 45(9), 594-598.

Meullemiestre, A., Petitcolas, E., Maache-Rezzoug, Z., Chemat, F., \& Rezzoug, S. A. (2016). Impact of ultrasound on solid-liquid extraction of phenolic compounds from maritime pine sawdust waste. Kinetics, optimization and large scale experiments. Ultrasonics Sonochemistry, 28, 230-239.

Miguel, M. G., Faleiro, M. L., Guerreiro, A. C., \& Antunes, M. D. (2014). Arbutus unedo L.: Chemical and biological properties. Molecules, 19(10), 1579-15823.

Moch, R. W. (1986). Pathology of BHA-and BHT-induced lesions. Food and Chemical Toxicology, 24, 1167-1169.

Montesano, D., Cossignani, L., D'Arco, G., Simonetti, M. S., \& Damiani, P. (2006). Pure lycopene from tomato preserves extra virgin olive oil from natural oxidative events during storage. JAOCS-Journal of the American Oil Chemists' Society, 83(11), 933-941.

Montesano, D., Fallarino, F., Cossignani, L., Bosi, A., Simonetti, M. S., Puccetti, P., \& Damiani, P. (2008). Innovative extraction procedure for obtaining high pure lycopene from tomato. European Food Research and Technology, 226(3), 327-335.

Mortensen, A. B., Wallin, H., Appelqvist, L. A., Everitt, G., Gref, C. G., Jacobsen, J., \& Julshamn, K. (1989). Gravimetric determination of ash in foods: NMKL collaborative study. Journal - Association of Official Analytical Chemists, 72(3), 481-483.

Naguib, Y. M. (2000). A fluorometric method for measurement of oxygen radicalscavenging activity of water-soluble antioxidants. Analytical Biochemistry, 284(1), 93-98.

Naviglio, D., Montesano, D., \& Gallo, M. (2015). Laboratory production of lemon liqueur (Limoncello) by conventional maceration and a two-syringe system to illustrate rapid solid-liquid dynamic extraction. Journal of Chemical Education, 92(5), 911-915.

Naziri, E., Nenadis, N., Mantzouridou, F. T., \& Tsimidou, M. Z. (2014). Valorization of the major agrifood industrial by-products and waste from Central Macedonia (Greece) for the recovery of compounds for food applications. Food Research International, 65 (PC), 350-358.

Obón, J. M., Castellar, M. R., Cascales, J.a., \& Fernández-López, J.a. (2005). Assessment of the TEAC method for determining the antioxidant capacity of synthetic red food colorants. Food Research International, 38(8-9), 843-845.

Özcan, M. M., \& Hacıseferoğulları, H. (2007). The Strawberry (Arbutus unedo L.) fruits: Chemical composition, physical properties and mineral contents. Journal of Food Engineering, 78(3), 1022-1028.

Ozgen, M., Reese, R. N., Tulio, A. Z., Scheerens, J. C., \& Miller, A. R. (2006). Modified 2,2azino-bis-3-ethylbenzothiazoline-6-sulfonic acid (ABTS) method to measure antioxidant capacity of selected small fruits and comparison to ferric reducing antioxidant power (FRAP) and 2,2'-diphenyl-1-picrylhydrazyl (DPPH) methods. Journal of Agricultural and Food Chemistry, 54(4), 1151-1157.

Pereira, C., Barros, L., Carvalho, A. M., \& Ferreira, I. C. F. R. (2011). Nutritional composition and bioactive properties of commonly consumed wild greens: Potential sources for new trends in modern diets. Food Research International, 44(9), 2634-2640.

Périno, S., Pierson, J. T., Ruiz, K., Cravotto, G., \& Chemat, F. (2016). Laboratory to pilot scale: Microwave extraction for polyphenols lettuce. Food Chemistry, 204, 108-114.

Pinela, J., Barros, L., Carvalho, A. M., \& Ferreira, I. C. F. R. (2012). Nutritional composition and antioxidant activity of four tomato (Lycopersicon esculentum L.) farmer varieties in Northeastern Portugal homegardens. Food and Chemical Toxicology, 50(3-4), 829-834.

Pinela, J., Prieto, M. A., Barreiro, M. F., Carvalho, A. M., Oliveira, M. B. P. P., Vázquez, J. A., \& Ferreira, I. C. F. R. (2016). Optimization of microwave-assisted extraction of hydrophilic and lipophilic antioxidants from a surplus tomato crop by response surface methodology. Food and Bioproducts Processing, 98, 283-298.

Prieto, M. A., Curran, T. P., Gowen, A., \& Vázquez, J. A. (2015). An efficient methodology for quantification of synergy and antagonism in single electron transfer antioxidant assays. Food Research International, 67, 284-298.

Prieto, M. A., Murado, M. A., Rodríguez-Amado, I., \& Vázquez, J. A. (2012). ß-Carotene assay revisited. Application to characterize and quantify antioxidant and prooxidant activities in a microplate. Journal of Agricultural and Food Chemistry, 60(36), 8983-8993.

Prieto, M. A., Murado, M. A., Vázquez, J. A., \& Curran, T. P. (2013). A new microplate procedure for simultaneous assessment of lipophilic and hydrophilic antioxidants and pro-oxidants, using crocin and $\beta$-carotene bleaching methods in a single combined assay: Tea extracts as a case study. Food Research International, 53(2), 836-846.

Prieto, M. A., \& Vázquez, J. A. (2014). In vitro determination of the lipophilic and hydrophilic antioxidant capacity of unroasted coffee bean extracts and their synergistic and antagonistic effects. Food Research International, 62(10), 1183-1196.

Prieto, M. A., Vázquez, J. A., \& Murado, M. A. (2014). A critical point: The problems associated with the variety of criteria to quantify the antioxidant capacity. Journal of Agricultural and Food Chemestry, 62(24), 5472-5484.

Prieto, M. A., Vázquez, J. A., \& Murado, M. A. (2015). Crocin bleaching antioxidant assay revisited: Application to microplate to analyse antioxidant and pro-oxidant activities. Food Chemistry, 1(167), 299-310.

Re, R., Pellegrini, N., Proteggente, A., Pannala, A., Yang, M., \& Rice-Evans, C. (1999). Antioxidant activity applying an improved ABTS radical cation decolorization assay. Free Radical Biology and Medicine, 26(9-10), 1231-1237.

Shahidi, F., \& Zhong, Y. (2015). Measurement of antioxidant activity. Journal of Functional Foods, 18(Part B), 757-781.

Sharma, O. P., \& Bhat, T. K. (2009). DPPH antioxidant assay revisited. Food Chemistry, 113(4), 1202-1205.

Simić, V. M., Rajković, K. M., Stojičević, S. S., Veličković, D. T., Nikolić, N.Č., Lazić, M. L., \& Karabegović, I. T. (2016). Optimization of microwave-assisted extraction of total 
polyphenolic compounds from chokeberries by response surface methodology and artificial neural network. Separation and Purification Technology, 160, 89-97.

Soria, A. C., \& Villamiel, M. (2010). Effect of ultrasound on the technological properties and bioactivity of food: A review. Trends in Food Science and Technology, 21(7), 323-331.

Strickland, J. D. H., \& Parsons, T. R. (1968). A practical handbook of seawater analysis. (Secound edition). Journal of the Fisheries Research Board of Canada(pp. 1-311). Ottawa.

Thoo, Y., Ho, S. K., Liang, J. Y., Ho, C. W., \& Tan, C. P. (2010). Effects of binary solvent extraction system, extraction time and extraction temperature on phenolic antioxidants and antioxidant capacity from mengkudu (Morinda citrifolia). Food Chemistry, 120(1), 290-295.

Tomšik, A., Pavlić, B., Vladić, J., Ramić, M., Brindza, J., \& Vidović, S. (2016) Optimization of ultrasound-assisted extraction of bioactive compounds from wild garlic (Allium ursinum L.). Ultrasonics Sonochemistry, 29, 502-511.

Torrado, A., Vázquez, J. A., Prieto, M. A., Fuciños, P., Montemayor, M., Pastrana, L., \& Murado, M. A. (2013). Amylase production by Aspergillus oryzae in a solid-state bioreactor with fed-batch operation using mussel processing wastewaters as feeding medium. Journal of Chemical Technology and Biotechnology, 88(2), 226-236.

Wang, L., \& Weller, C. L. (2006). Recent advances in extraction of nutraceuticals from plants. Trends in Food Science and Technology, 17(6), 300-312.

Weibull, W., \& Sweden, S. (1951). A statistical distribution function of wide applicability. Journal of Applied Mechanics, 18(3), 293-297.

Wong, W. H., Lee, W. X., Ramanan, R. N., Tee, L. H., Kong, K. W., Galanakis, C. M., \& Prasad, K. N. (2015). Two level half factorial design for the extraction of phenolics, flavonoids and antioxidants recovery from palm kernel by-product. Industrial Crops and Products, 63, 238-248.

Zhang, P., \& Omaye, S. (2001). Antioxidant and prooxidant roles for $\beta$-carotene, $\alpha$-tocopherol and ascorbic acid in human lung cells. Toxicology In Vitro, 15, 13-24.

Zhu, Z., Guan, Q., Koubaa, M., Barba, F. J., Roohinejad, S., Cravotto, G., \& He, J. (2017). HPLC-DAD-ESI-MS2 analytical profile of extracts obtained from purple sweet potato after green ultrasound-assisted extraction. Food Chemistry, 215, 391-400.

Zhu, Z., He, J., Liu, G., Barba, F. J., Koubaa, M., Ding, L., \& Vorobiev, E. (2016). Recent insights for the green recovery of inulin from plant food materials using non-conventional extraction technologies: A review. Innovative Food Science \& Emerging Technologies, 33, 1-9. 